Check for updates

Cite this: Mater. Adv., 2021, 2, 5881

Received 8th April 2021,

Accepted 7th August 2021

DOI: 10.1039/d1ma00315a

rsc.li/materials-advances

\section{A review on biomass-derived hard carbon materials for sodium-ion batteries}

\author{
Mathew Thompson, Qingbing Xia, Zhe Hu and Xiu Song Zhao (D)*
}

\section{Introduction}

\subsection{The need for electrochemical energy storage systems}

Fossil fuels such as coal, oil and gas are significant contributors of greenhouse gases, such as $\mathrm{CO}_{2}$ and $\mathrm{CH}_{4}$. The Intergovernmental Panel on Climate Change (IPCC) suggests that reduction in use of fossil fuels is required to ensure the average global temperature rise does not exceed $2{ }^{\circ} \mathrm{C}$ within this century. ${ }^{1}$ Providing affordable and clean energy is one of the seventeen Sustainable Development Goals (SDGs) outlined by the United Nations in response to recommendations provided by the IPCC. $^{2}$ In the context of Australia, the federal government is ambitious to cut fossil fuel emissions by at least $50 \%$ by $2050 .^{3}$ Moving from non-renewable to renewable energy sources has been outlined as an important factor to achieve this goal.

Solar photovoltaics (PV) and wind energy are renewable energy technologies currently being deployed worldwide. ${ }^{4}$ However, these renewable energy sources are intermittent in production, and as such are unable to provide energy on demand reliably on a large scale. Due to this intermittency problem, the widespread global uptake of the above-mentioned renewable energy sources has been limited. To increase the contribution of PV and wind energy and the total energy consumed by renewable sources, research and development of innovative large-scale energy storage devices is required

School of Chemical Engineering, The University of Queensland, St Lucia, QLD 4072, Australia. E-mail: george.zhao@uq.edu.au to store and distribute intermittent renewable energy as and when it is in demand. However, for several reasons, such as resource availability and performance failures, large scale energy storage has been identified as the current bottleneck towards wide deployment of renewable energy.

Lithium-ion batteries (LIBs) are the main electrochemical energy storage technology used within portable electronics, electric vehicles, and more recently for the storage of energy produced by wind and solar renewables. ${ }^{7}$ The high energy density of LIBs enables this technology to supply consistent energy over an extended period of time. ${ }^{8}$ For example, the introduction of the Tesla-Neoen 100 megawatt (MW) lithiumion grid-scale battery system installed in South Australia to support the previously established wind farm and provide much needed stabilisation to the state's energy grid. ${ }^{9}$ However, the rapidly growing demand for electrochemical energy storage systems to aid the implementation of renewable energy infrastructure is increasing the pressure on lithium resources. Also, the politically sensitive location of lithium reserves results in additional concerns. It is under this background that sodiumion batteries (NIBs) have resurfaced to attract intensive research and development attention in both academics and industry in recent years.

\subsection{Why sodium-ion batteries?}

There are a number of parameters to be considered in developing energy storage technologies, such as the 
cost per $\mathrm{kW} \mathrm{h}\left(\$ \mathrm{~kW}^{-1} \mathrm{~h}^{-1}\right)$, the specific energy (gravimetric $\mathrm{W} \mathrm{h} \mathrm{kg}{ }^{-1}$, or volumetric energy density $\mathrm{W} \mathrm{h}^{-1}$ ), the specific power $\left(\mathrm{W} \mathrm{kg}^{-1}\right)$, and the sustainability of the materials used. As it stands, LIBs currently dominate the energy storage market globally with competitive price (SUSD $153 \mathrm{~kW}^{-1} \mathrm{~h}^{-1}$ ) ${ }^{10}$ and high energy density $\left(260 \mathrm{~W} \mathrm{~h} \mathrm{~kg}{ }^{-1}\right) .{ }^{11}$ However, the energy density of LIBs is close to reaching its maximum intrinsic energy density of around $300 \mathrm{~W} \mathrm{~h} \mathrm{~kg}{ }^{-1} \cdot{ }^{11}$ On the other hand, the low abundance and uneven global distribution of lithium resources cause concerns on the sustainability of the LIB technology. Also, with the fast development of electric vehicles (EVs) and growing needs for grid-scale energy storage, the demand for lithium and cobalt resources is rapidly increasing, potentially causing price rise.

In comparison with lithium, sodium is significantly more abundant and widely distributed throughout the globe. ${ }^{12}$ Thus, the cost of sodium is far less than lithium (Table 1). Additionally, sodium ions are non-reactive with aluminium. As a result, aluminium can be used as the current collector for NIBs. The use of aluminium instead of copper as the current collector further reduces the overall cost of the cell. According to Passerini et al. ${ }^{14}$ replacing lithium with sodium as the charge carrier and copper with aluminium as the current collector enables about $20 \%$ reduction in cost (Fig. 1). Thus, NIBs are more cost-effective than LIBs. ${ }^{14}$

Moreover, there are fundamental differences in physical and chemical properties between the two alkali metal ions (Table 1). Sodium is a weaker Lewis acid than lithium, leading to a lower de-solvation energy of the former than the latter in most organic solvents. ${ }^{16}$ This property is particularly significant in terms of ionic conductivity and interfacial mass transport. ${ }^{17,18}$

\subsection{Challenges and opportunities of sodium-ion batteries}

The configuration of a NIB is like LIBs. The individual components that make up the sodium-ion rechargeable battery include an anode, a cathode, a separator and the electrolyte. ${ }^{19-21}$ However, due to the differences in chemistry between lithium and sodium ions, the interaction of the alkali metal ions with host materials previously developed for LIBs differ significantly. Graphite with a theoretical lithium-ion storage capacity of $372 \mathrm{~mA} \mathrm{~h} \mathrm{~g} \mathrm{~g}^{-122}$ is the most popularly used anode in LIB cells. The storage capacity of sodium ions in graphite however is limited in traditional ester-based electrolytes, with a storage capacity of about $31 \mathrm{~mA} \mathrm{~h} \mathrm{~g}^{-123}$ This is

Table 1 Comparison of key properties between lithium and sodium ${ }^{15}$

\begin{tabular}{lll}
\hline Property & $\mathrm{Na}$ & $\mathrm{Li}$ \\
\hline Cation radius & $97 \mathrm{pm}$ & $68 \mathrm{pm}$ \\
Atomic weight & $23 \mathrm{~g} \mathrm{~mol}$ & $6.9 \mathrm{~g} \mathrm{~mol}^{-1}$ \\
$E_{0} v s$. SHE & $-2.7 \mathrm{~V}$ & $-3.04 \mathrm{~V}$ \\
A-O coordination & Octahedral or prismatic & Octahedral or tetrahedral \\
Melting point & $97.7{ }^{\circ} \mathrm{C}$ & $180.5{ }^{\circ} \mathrm{C}$ \\
Abundance & $23.6 \times 10^{3} \mathrm{mg} \mathrm{kg}^{-1}$ & $20 \mathrm{mg} \mathrm{kg}^{-1}$ \\
Distribution & Everywhere & $70 \%$ in South America \\
Price, carbonates & About 2 RMB per kg & About 40 RMB per kg
\end{tabular}

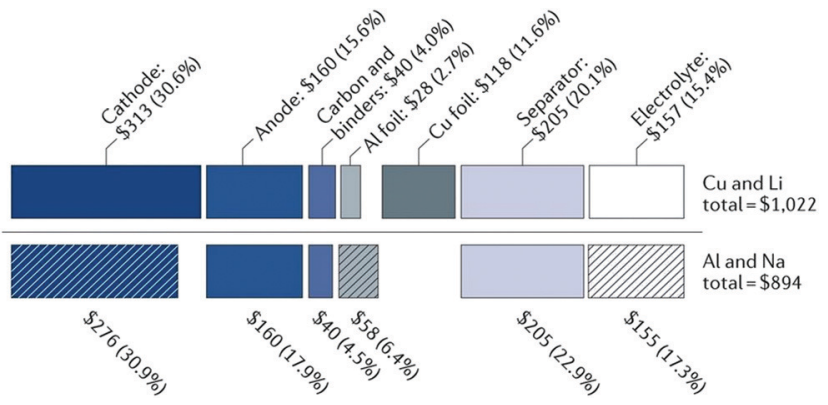

Fig. 1 A cost comparison between lithium-ion and sodium-ion batteries. ${ }^{13}$ Copyright 2001, Springer Nature.

attributed to the thermodynamically unstable nature of sodium-graphite intercalation compounds. ${ }^{24,25}$ It should be pointed out, however, that the co-intercalation mechanism in ether-based electrolytes can enable a larger amount of sodium ion storage in graphite (about $\left.100 \mathrm{~mA} \mathrm{~h}^{-1}\right)^{26}$ The difference in chemistry between lithium and sodium impacts the electrochemical properties of the alkali metal ions in positive electrodes as well. For instance, $\mathrm{LiFePO}_{4}$ exhibits a voltage of $3.5 \mathrm{~V}$ and a capacity of $160 \mathrm{~mA} \mathrm{~h} \mathrm{~g}{ }^{-1}$, higher than that of $\mathrm{NaFePO}_{4}$ (3.0 $\mathrm{V}$ and $110 \mathrm{~mA} \mathrm{~h} \mathrm{~g}{ }^{-1}$ ). According to Wang et al., ${ }^{26}$ these differences are attributed to the larger charge transfer resistance due to the increased ionic radius of the sodium ion compared to the lithium ion. Therefore, research into new electrode materials and electrolytes are required to fully realise the potential of NIBs.

The general requirements of anode materials in NIBs include the ability to store adequate quantities of sodium ions, having a similar voltage potential to that of pure sodium metal, ${ }^{27}$ stability towards electrolytes, high electronic and ionic conductivity and low cost with little environmental impact. ${ }^{4}$ Anode materials used in NIBs can be classified into three categories based on their charge storage mechanisms: (1) insertion materials such as carbonaceous materials and titanium oxides, (2) conversion materials such as transition metal oxides and sulphides, and (3) alloying materials such as group 14 and 15 elements. ${ }^{28,29}$ Although conversion and alloying materials are promising anode materials for sodium-ion storage, the larger ionic radii of Na-ions can result in large expansion of unit cell and degradation and exfoliation of the material upon cycling, leading to voltage hysteresis and low reversible capacities. ${ }^{28,30}$ The insertion-based materials, such as hard carbon (HC), soft carbon (SC) and graphite accept ionic species without significant volume change during sodiation and de-sodiation. ${ }^{4}$ This traits makes carbonaceous insertion based materials suitable candidates for NIBs. Moreover, HC can be obtained from biomass, meaning it can be low in cost and environmental impact.

The sodium-ion storage capacity in HC is significantly higher than in graphite. ${ }^{25}$ However, the cycle life is still far less than the requirements for realising grid-scale energy storage. ${ }^{31}$ According to Xiao et al. ${ }^{32}$ the cycle instability can be attributed to the undesirable side reactions caused by the 
reduction reaction of the electrolyte on the anode side. By significantly reducing the surface area of a sucrose-derived HC to as low as $1.74 \mathrm{~m}^{2} \mathrm{~g}^{-1}$, the authors were able to obtain an initial coulombic efficiency of $86.1 \%$ with capacity retention of $93.4 \%$ after 100 cycles. However, the rate performance is restricted due to the diffusion-controlled kinetics of the electrochemical reaction. As a result, understanding the microstructure/performance relationship of sodium-ion storage in $\mathrm{HC}$ is important to underpin the development of the NIB technology.

\subsection{Scope and aim of this review}

This review aims to provide a summary of recent research progress towards biomass-derived HC materials for sodiumion storage. It is particularly focused on analysing the relationship between biomass precursors, processing methods and conditions, HC structure and electrochemical performance. Firstly, the debate on the mechanisms and models of sodium-ion storage in HC materials in the literature space is briefly outlined. Secondly, the biomass precursors and general methods for processing biomass to prepare HC materials are discussed. Thirdly, the important conditions influencing the physical and chemical properties of the resulting HC materials are presented. Then, the relationship between HC properties and electrochemical performance is analysed focusing on the role of surface defects and functionalities, porosity and graphitic domains.

\section{Sodium ion storage mechanisms in hard carbon}

\subsection{Microstructure of hard carbon}

$\mathrm{HC}$ is a non-graphitisable carbon allotrope even at temperatures as high as $3000{ }^{\circ} \mathrm{C}$. Another carbon allotrope that is also being explored as a sodium-ion host material is soft carbon (SC). ${ }^{33}$ Unlike HC, SC can be readily converted to graphite by heating to high temperatures (e.g., $\left.3000{ }^{\circ} \mathrm{C}\right)$. The physical properties of HC and SC are quite different. Fig. 2 schematically compares the microstructures of graphite, SC and HC. ${ }^{34}$ Both graphite and SC are more structurally ordered with a $d$-spacing close to $0.335 \mathrm{~nm}$. In comparison, the $d$-spacing of $\mathrm{HC}$ is larger than that of $0.335 \mathrm{~nm}$. Both $\mathrm{HC}$ and SC possess pores, but the latter has a much lower porosity than the former. As a result, the higher porous volume and expanded $d$-spacing enable $\mathrm{HC}$ materials to exhibit a significantly higher sodium-ion storage capacity than SC and graphite. Thus, amongst all carbon allotropes, HC stands out as a promising anode for sodium-ion storage. $^{35}$

HC materials are produced by heating thermosetting carbon-containing precursors in the absence of oxygen (pyrolysis) (Fig. 3). Instead, thermoplastic precursors are used to prepare SC and graphite. ${ }^{36}$ Biomass, a type of thermosetting precursor, is a sustainable and naturally abundant source for preparing $\mathrm{HC}$ materials for energy storage applications. ${ }^{36,37}$ Both the physical and chemical properties of biomass-derived HCs have impact on sodium-ion storage performance. ${ }^{11,23,35}$ Chemically, the biomass-derived HCs primarily consist of carbon, oxygen and nitrogen. While oxygen and nitrogen are present in small amounts, they can have significant influence on the electronic, chemical and electrochemical properties of the HC. Physically, the presence of heteroatoms along with $\mathrm{sp}^{3}$ hybridised crosslinking carbon bonds lead to the formation of short-range graphitic ordering (turbostratic nanodomains) and pores, including both open and closed pores. ${ }^{38,39}$ Due to this arrangement, HC also typically has a large specific surface area. ${ }^{40}$ The unique microstructural features of HCs provide a number of possibilities for sodium ion storage. ${ }^{41}$

\subsection{Sodium-ion storage mechanisms in hard carbon}

Since the pioneering work of Stevens and Dahn in $2000,{ }^{42}$ sodium-ion storage mechanisms in HC materials have been in debate. This is not unexpected because of the diversity of HC samples prepared using different precursors and under different processing conditions, as well as the difficulty in characterising the physical and chemical properties, which have effect on sodium-ion storage behaviour during electrochemical cycling. Nevertheless, a recent review summarises four possible sodium-ion storage models for $\mathrm{HC}$ as illustrated in Fig. 4, including (a) the intercalation-pore filling model, (b) the adsorption-intercalation model, (c) the adsorption-pore filling model and (d) the adsorption-intercalation-pore filling model. $^{35}$

2.2.1. The intercalation-pore filling model. In 2000, Stevens \& Dahn proposed that sodium ions are stored in $\mathrm{HC}$ materials via the intercalation-pore filling model. ${ }^{42}$ From the galvanostatic charge-discharge (GCD) curves, the authors observed an initial drop in voltage known as the sloping voltage region above $0.1 \mathrm{~V}$. They attributed this region to sodium-ion

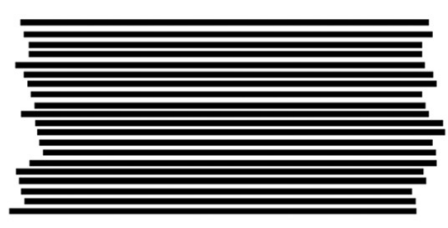

Graphite

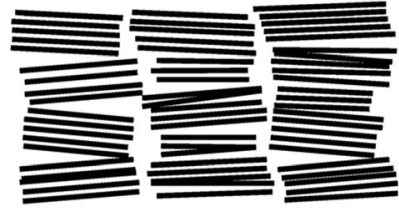

Soft (disordered, graphitizable) carbon

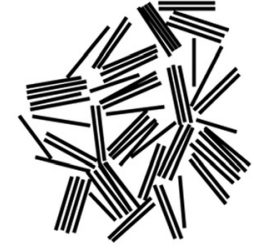

Hard(disordered, nongraphitizable)carbon

Fig. 2 Scheme illustrating the microstructures of graphite, soft carbon and hard carbon. ${ }^{34}$ Copyright 2001, Wiley. 


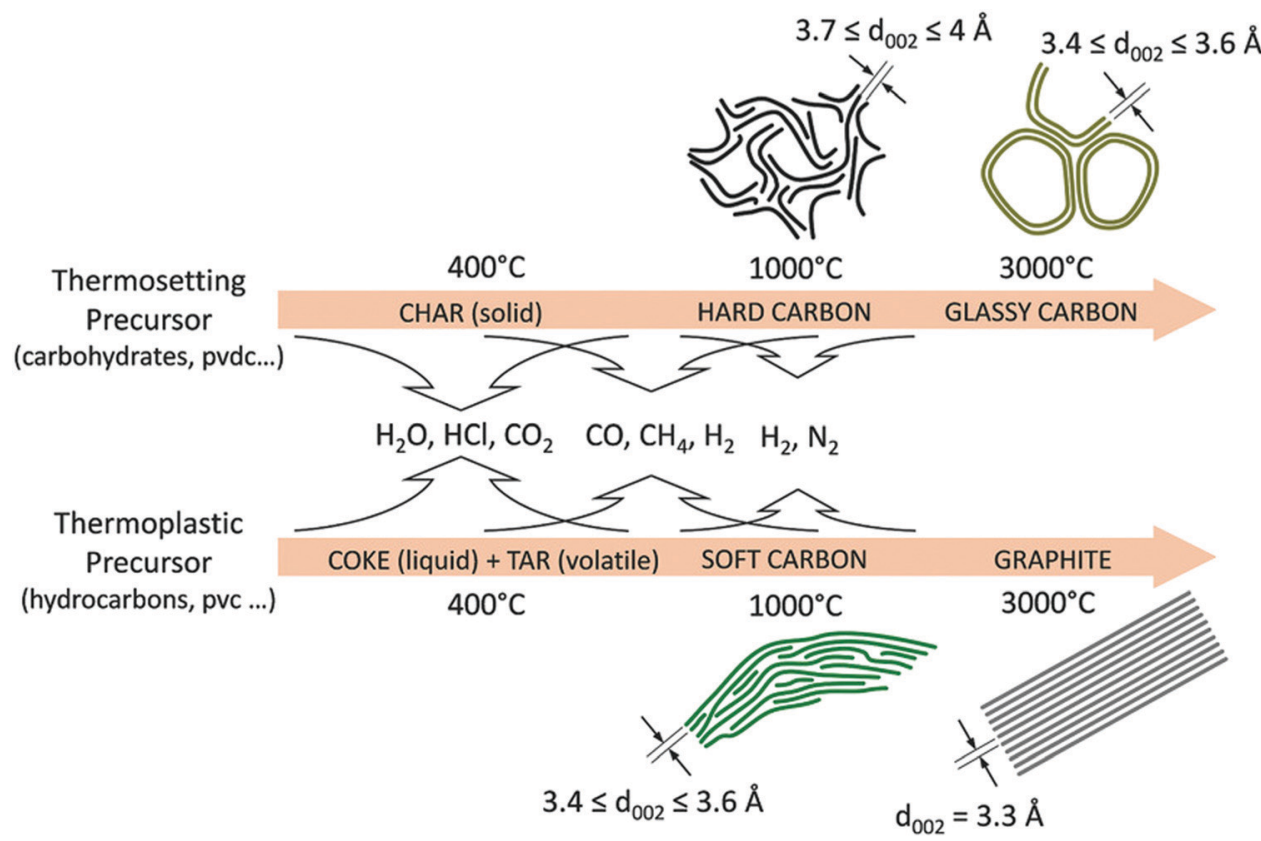

Fig. 3 Schematic illustration of the evolution of the microstructures of graphite, soft and HCs from different biomass precursors as a function of thermal treatment temperatures. ${ }^{36}$ Copyright 2018 , Wiley.
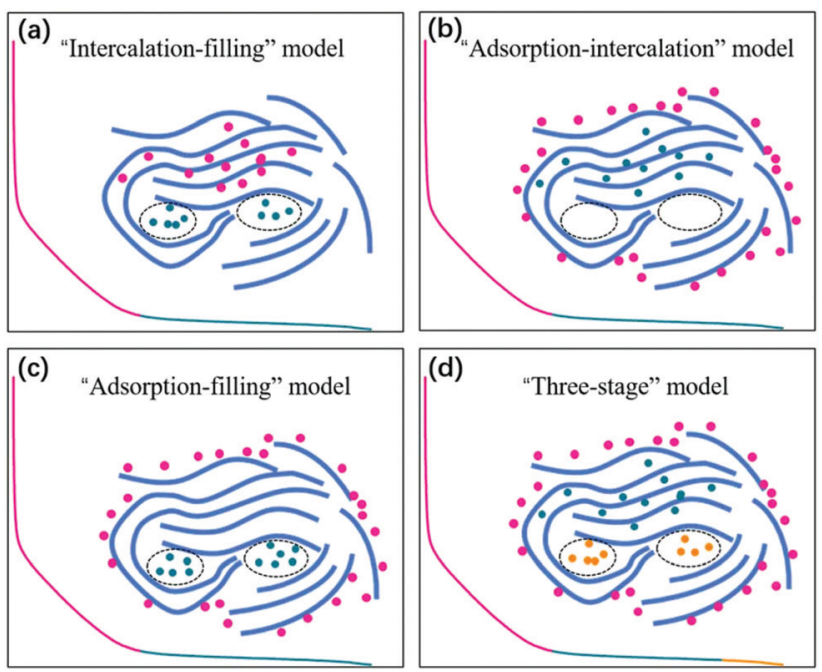

Fig. 4 Schematic illustration of the (a) intercalation-pore filling model, (b) adsorption-intercalation model, (c) adsorption-pore filling model, and (d) adsorption-intercalation-pore filling model. ${ }^{35}$ Copyright 2020, IOPscience.

intercalation into the graphitic domains in $\mathrm{HC}$ as sequential sodiation would result in a progressive drop in voltage potential. For the extended capacity region below $0.1 \mathrm{~V}$ which is close to the voltage of sodium metal, it was assigned to the pore filling by sodium in the pores of HC to form sodium metals. A subsequent study by the authors using the in situ small-angle X-ray scattering (SAXS) characterisation technique revealed a decrease in scattering intensity as the voltage dropped below $0.1 \mathrm{~V}$ (Fig. 5). In the slop discharge region (between point $a$ to point $b$ in the GCD curve in Fig. 5f), the

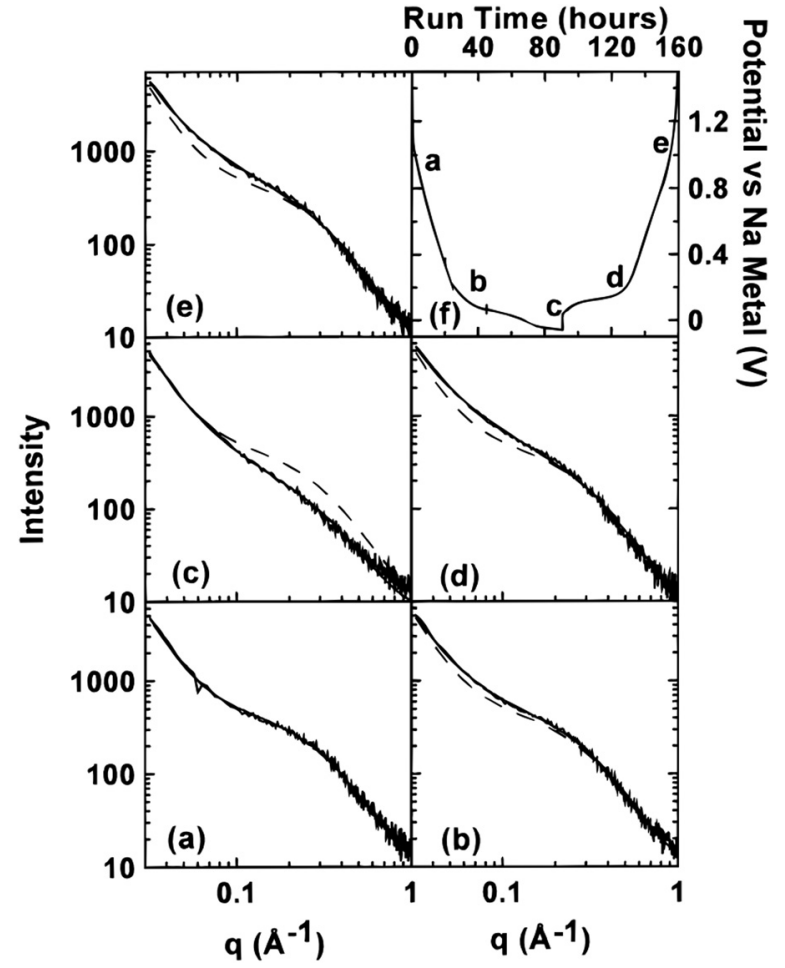

Fig. 5 SAXS patterns of (a) unsodiated $H C$, (b) sodiated $H C$ approaching $0.1 \mathrm{~V}$ on discharge cycle, (c) sodiated $\mathrm{HC}$ below $0.1 \mathrm{~V}$ on discharge cycle, (d) sodiated $\mathrm{HC}$ approaching $0.1 \mathrm{~V}$ on charge cycle, and (e) fully desodiated $\mathrm{HC}$. The dash lines in $(\mathrm{b}-\mathrm{e})$ are the curves fitted to the data in (a). (f) Potential of cells versus sodium metal. ${ }^{43}$ Copyright 2000, IOPscience.

scatting intensity at low angels gradually decreased, which was be believed to the development of microcracks in the 


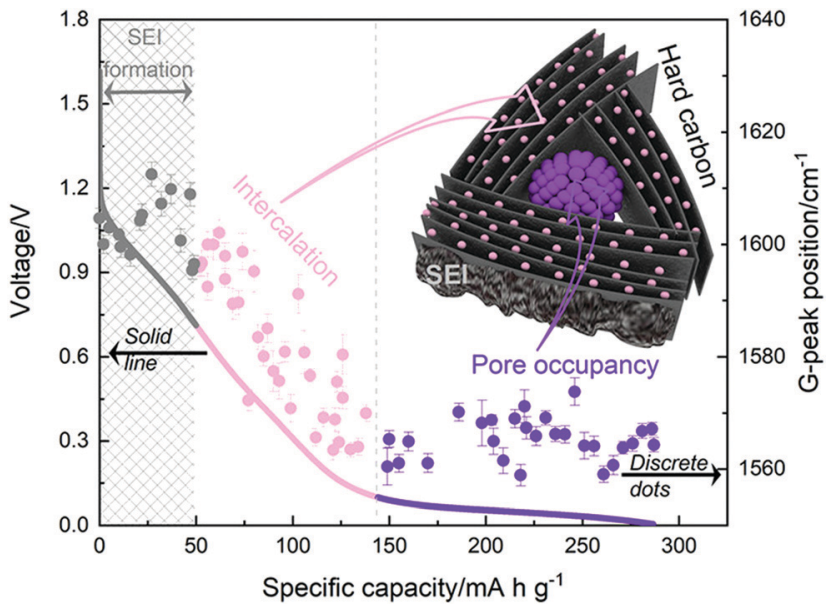

Fig. 6 The GCD profile (solid line) and relative G-band peak position (discrete dots) during first discharge cycle: grey (line and dots) refers to the formation of solid electrolyte interface (SEI), pink (line and dots) refers to intercalation of sodium-ions between graphene layers, and purple (line and dots) refers to filling of sodium ions in pores. ${ }^{46}$ Copyright 2020, American Chemical Society.

nanoporous carbon associated with the expansion caused by sodium insertion (i.e., $\mathrm{Na}^{+}$intercalation process). Upon further discharge the cell along the low voltage plateau region (from point $b$ to point $c$ in the GCD curve in Fig. 5f), the scatting intensity of the nanopores decreased, and become difficult to differentiate from background scatting near the end of discharge. Such a variation clearly reveals that the sodium enters the nanopores (pore filling process), which effectively decrease the contrast between the pores and the carbon matrix by increasing the electron density in the pores. ${ }^{43}$

More recently, operando Raman spectroscopy studies were used to observe G- and D-band energies during sodiation and desodiation. The G-band at $\sim 1590 \mathrm{~cm}^{-1}$ corresponds with graphene sheets producing Raman scattering from $E_{2 g}$ symmetry. ${ }^{44,45}$ A shift to lower G-band peak position during sodiation indicates electron transfer from intercalated sodiumions into the conduction bands of the graphene planes. Weaving et al., ${ }^{46}$ observed a steady decrease in energy of the G-band coinciding with the voltage region between 0.7 and $0.1 \mathrm{~V}$. This result suggests intercalation of sodium ions occurred in the higher voltage sloping region of the voltage capacity curves (Fig. 6). In comparison, the G-band peak position did not shift as the cell voltage dropped below $0.1 \mathrm{~V}$. Based on these findings, the authors proposed that sodium-ion storage proceeds via intercalation in the high voltage region and porefilling in the low voltage region, in good agreement with that of Stevens and Dahn. ${ }^{43,44}$

2.2.2. The adsorption-intercalation model. Using in situ Raman spectroscopy to study the dynamic interactions between sodium ions and HC, Lyu et al. ${ }^{47}$ compared HC samples with different degrees of graphitisation and variation in surface properties (Fig. 7a and b). In this study, mushroom spore derived HC samples prepared at 900 and $1400{ }^{\circ} \mathrm{C}$ with different specific surface areas $\left(329.6 \mathrm{~m}^{2} \mathrm{~g}^{-1}\right.$ and $\left.14.7 \mathrm{~m}^{2} \mathrm{~g}^{-1}\right)$ and different degrees of graphitisation $\left(I_{\mathrm{G}} / I_{\mathrm{D} 3}\right.$ of 1.21 and 1.80$)$ were investigated. Interestingly, the GCD profiles for the sample prepared at $900{ }^{\circ} \mathrm{C}$ displayed a large sloping capacity and reduced plateau capacity. The reverse was observed for the high-temperature carbonised sample. In situ Raman spectra showed that the D-band peak gradually disappeared as the cell was discharged for the low-temperature carbonised sample, whereas little variation was observed from the G-band. This suggests sodium ions were predominantly stored at the surface defective sites with little contribution from intercalation for this HC sample. In comparison, the D-band remained relatively unchanged during discharge for the high-temperature carbonised sample. However, the G-band peak position remained consistent at approximately $1590 \mathrm{~cm}^{-1}$ above $0.1 \mathrm{~V}$, moved to lower frequency below $0.1 \mathrm{~V}$. According to the authors, the shift in peak position suggests sodium ions were inserted into the graphitic domains, contradicting to the observations by Weaving et $a l^{46}$ This study suggests sodium-ion intercalation between the graphene layers in HC occurs in the plateau region. ${ }^{47}$ To validate the sodium ion storage mechanism in the plateau region below $0.1 \mathrm{~V}$, Ding et $a{ }^{48}$ observed an increase in $d$-spacing using in situ X-ray diffraction (XRD) technique (Fig. $8 \mathrm{c}$ and d). As voltage approached $0.1 \mathrm{~V}$, increase in $d$-spacing became more and more apparent, indicating sodium ion intercalation between graphene layers of graphite domains. Subsequently, Cao et al. ${ }^{49}$ compared the GCD profiles of sodium-ion storage in the graphite and a hard carbon with a hollow nanowires morphology. The graphite sample, with a $d$ spacing of $0.335 \mathrm{~nm}$ exhibited a specific capacity of $10 \mathrm{~mA} \mathrm{~h} \mathrm{~g}^{-1}$ below $0.2 \mathrm{~V}$. The hard carbon with a $d$-spacing of $0.37 \mathrm{~nm}$, however, delivered a capacity of $150 \mathrm{~mA} \mathrm{~h} \mathrm{~g}^{-1}$ below $0.2 \mathrm{~V}$. The authors concluded that the low-voltage plateau is due to sodium ion intercalation into graphitic nanodomains.

2.2.3. The adsorption-pore filling model. Although Ding et $a{ }^{48}{ }^{48}$ observed an increase in $d$-spacing during progressive sodiation of HC when voltage approaches $0.1 \mathrm{~V}$ using the in situ $\mathrm{XRD}$ technique. This analytical technique for $\mathrm{HC}$ is however not easy to operate nor reliable because of the lack of long-range order of HC materials leading to broad diffraction peaks. ${ }^{36}$ Subsequent stu dies did not reproduce the same results. ${ }^{50,51}$ Lack in experimental consistency regarding the intercalation of sodium ions in $\mathrm{HC}$ led to further investigations. ${ }^{52-54}$ Bai et al. ${ }^{52}$ compared the physical and electrochemical properties of a sulphur-infused HC sample with that of a non-infused HC sample. The pristine HC sample exhibited a diffusioncontrolled behaviour with an extended plateau capacity (Fig. 8a), whilst the sulphur-infused HC showed a capacitive storage behaviour (Fig. 8b). Because the sulphur-infused sample had significantly reduced open porosity in comparison to the pristine HC (Fig. 8c), the reduction in diffusion-controlled sodium-ion storage capacity suggests that the low voltage plateau is the result of filling of sodium ions in the pores of the HC instead of intercalation. ${ }^{52}$ The studies provide reasonable explanation in favour of the adsorption-pore filling model, but the results are very much up to subjective interpretation. 

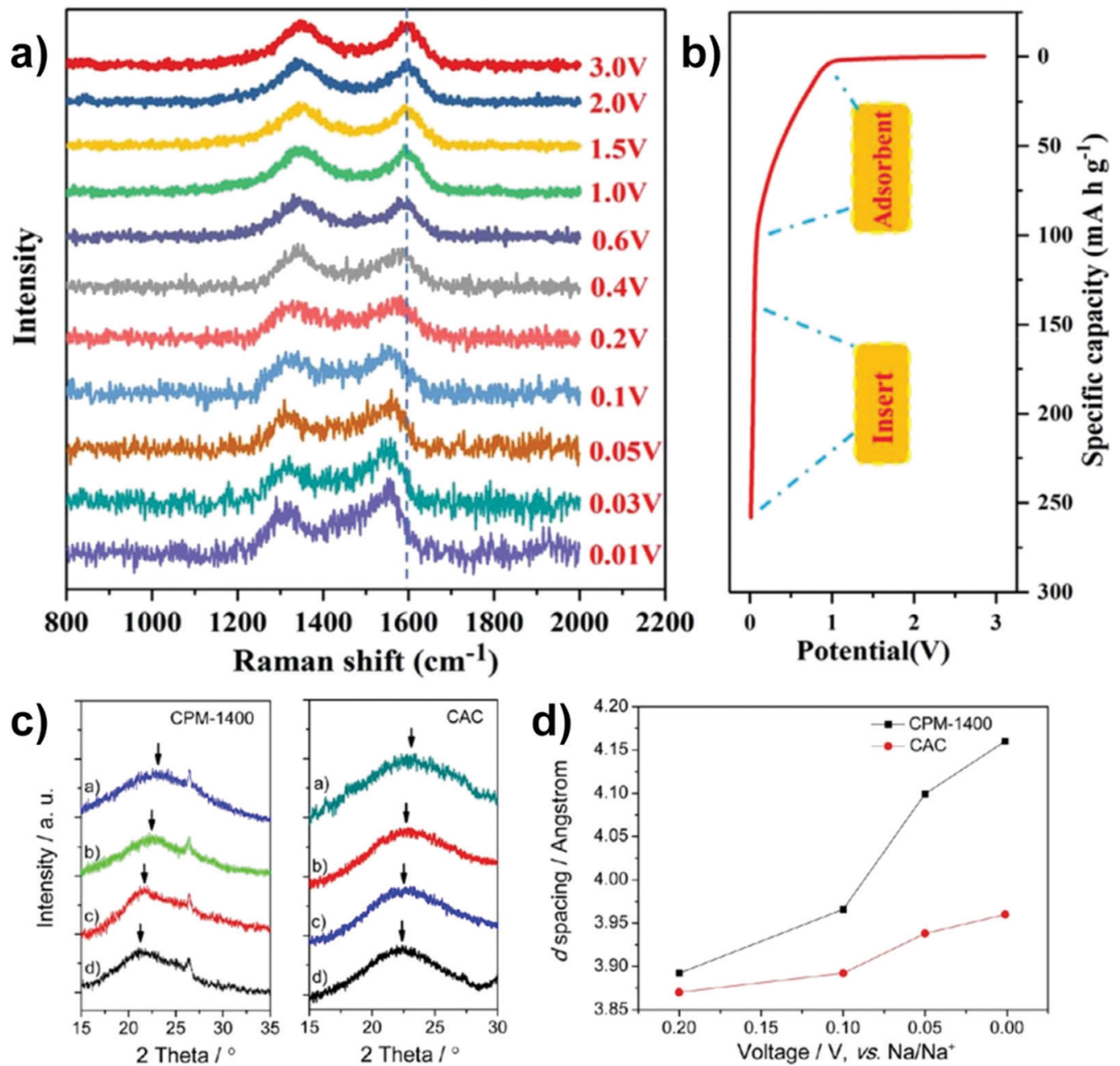

Fig. 7 In situ Raman spectra (a) with corresponding discharge states (b). ${ }^{47}$ Copyright 2021, Elsevier. XRD profiles (c) with corresponding $d$-spacing of (002) crystal plane(d). ${ }^{48}$ Copyright 2013, American Chemical Society.
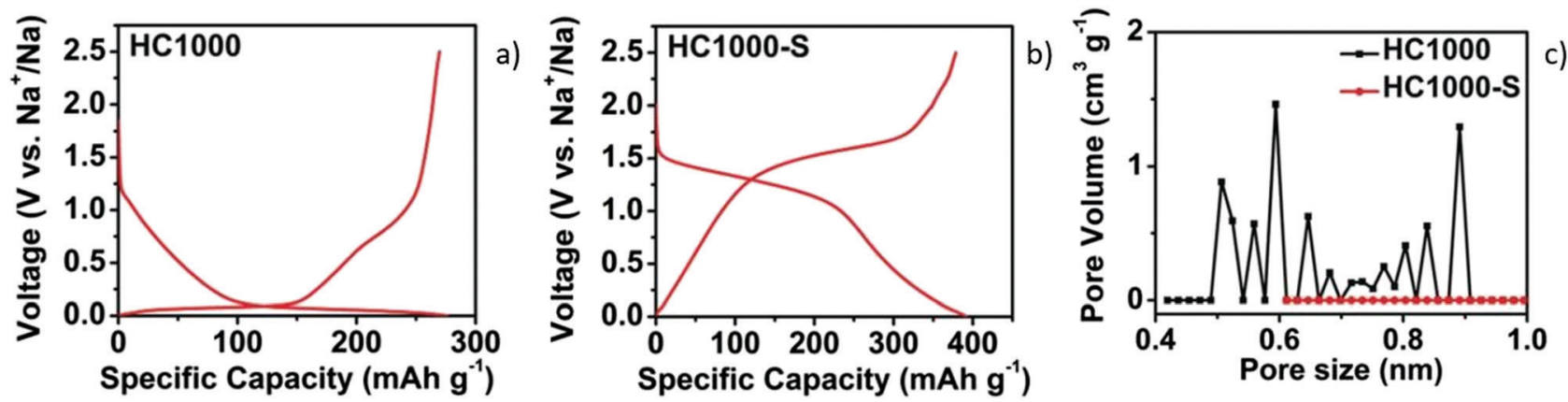

Fig. 8 GCD curves of HC samples without (a) and with sulphur filling in pores (b). (c) DFT pore size distribution curves of samples before (HC1000) and after sulphur filling (HC1000-S). ${ }^{52}$ Copyright 2018, Wiley.

2.2.4. The adsorption-intercalation-pore filling model. Recently, a model combining all of the three possible sodium ion storage mechanisms was proposed. ${ }^{55}$ This model suggests surface adsorption is the predominate storage mechanism above $0.1 \mathrm{~V}$. Below $0.1 \mathrm{~V}$, sodium-ion storage occurs firstly by intercalation into graphitic domains followed by filling in the pores of HC anode materials. ${ }^{19,35,54,56}$ According to Bommier et $a l .{ }^{56}$ the adsorption of sodium ions is sloping in GCD profiles because different defective sites (e.g., heteroatom sites, mono/di-vacancies and stone-wales defects) have different 

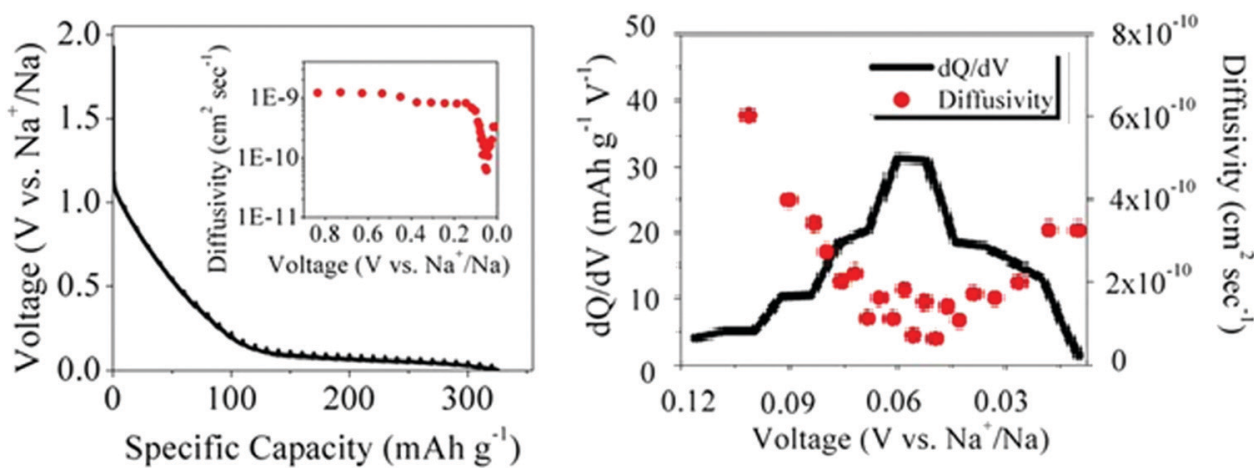

Fig. 9 (a) GITT discharge profiles and sodium-ion diffusivity (inset), and (b) variation of $d Q / d V$ and sodium-ion diffusivity as a function of voltage for a HC. ${ }^{56}$ Copyright 2015, American Chemical Society.

sodiation voltages. Also, the electron-deficient state of the defective carbon of these locations is energetically more favourable for sodium-ion adsorption, in comparison to intercalation and pore-filling. This explanation is supported by the galvanostatic intermittent titration (GITT) data in Fig. 9a, which shows that the diffusion of sodium ions is much faster at higher sloping potentials as a result of the more easily accessible adsorption sites. It is therefore a reasonable suggestion that sodium ions are first adsorbed on the surface of the HC in the sloping region of the GCD profile via the adsorption mechanism. The authors also noticed as voltage dropped from 0.1 to $0.05 \mathrm{~V}$, the diffusivity of sodium ions decreased with an increase in $\mathrm{d} Q / \mathrm{d} V$. However, between $0.05 \mathrm{~V}$ to the cut-off voltage, the diffusivity of sodium ions increased as $\mathrm{d} Q / \mathrm{d} V$ decreased (Fig. 9b). These observations suggest more than one sodium-ion storage mechanism are functioning in this low-voltage region.

To probe the proposed "three-stage" sodium-ion storage model, Jin $e t a l .{ }^{54}$ synthesised a series of resorcinol formaldehyde (RF) resin-derived HC samples with variation in physical properties. To elucidate the relationship between sodium-ion storage mechanism and HC properties, the authors compared the microstructural traits of HC prepared at different thermal treatment temperatures ranging between $800{ }^{\circ} \mathrm{C}$ and $1600{ }^{\circ} \mathrm{C}$ with observed electrochemical analysis. At low thermal treatment temperatures (below $1000{ }^{\circ} \mathrm{C}$ ), the microstructure was dominated by small graphitic domains with a high degree of cross-linking bonds and surface defect sites. At intermediate (a)
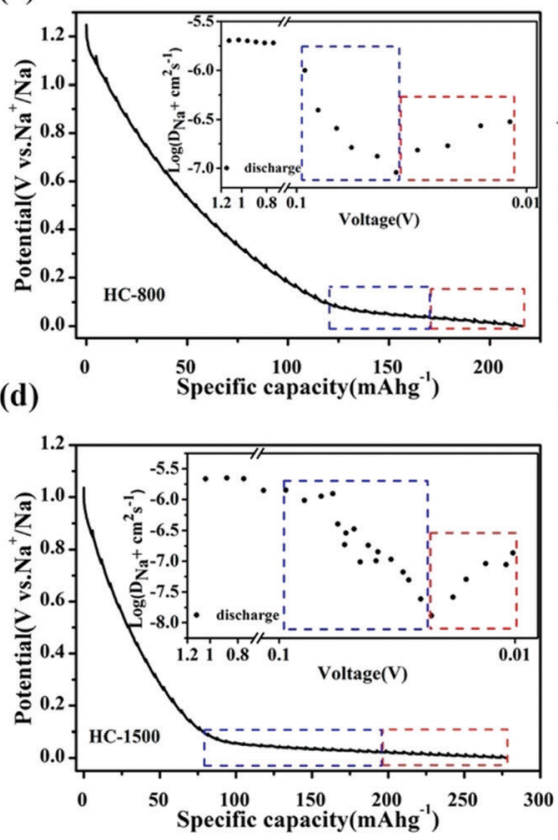

(b)

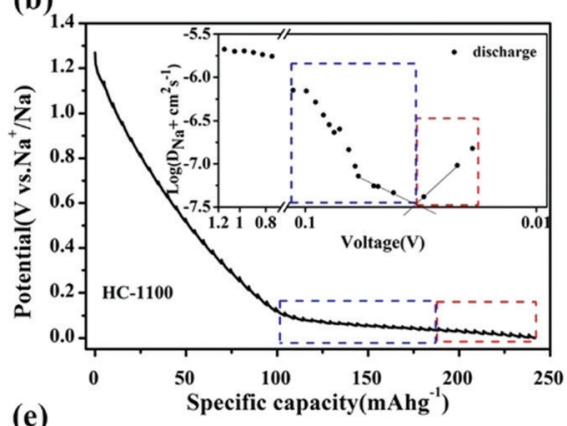

(e)

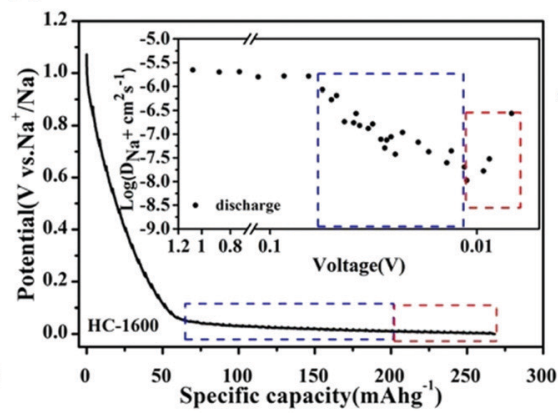

(c)

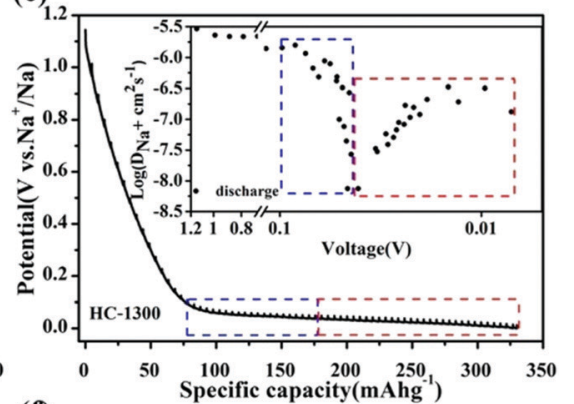

(f)

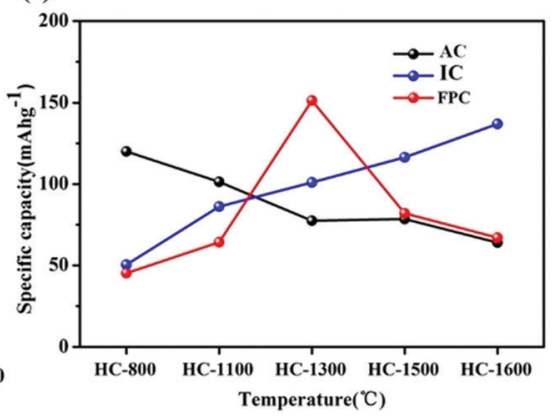

Fig. 10 GITT profiles of RF-derived $\mathrm{HC}$ samples carbonised at (a) $800{ }^{\circ} \mathrm{C}$, (b) $1100{ }^{\circ} \mathrm{C}$, (c) $1300{ }^{\circ} \mathrm{C}$, (d) $1500{ }^{\circ} \mathrm{C}$ and (e) $1600{ }^{\circ} \mathrm{C}$ with sodium ion storage contributions from intercalation (blue) and pore-filling (red) mechanisms. The insets show the sodium ion diffusion coefficients in the samples. (f) Relationship between adsorption (AC), intercalation (IC) and pore-filling (FPC) charge storage mechanisms and thermal treatment temperature. ${ }^{54}$ Copyright 2018, American Chemical Society. 
temperatures (above $1000{ }^{\circ} \mathrm{C}$, below $1300{ }^{\circ} \mathrm{C}$ ), the breakdown of cross-linking bonds and heteroatom content led to increased stacking of graphene layers, and formation of confined spaces (closed pores) inaccessible from the surface, located between the unevenly stacked graphene planes. At high temperatures (Above $1300{ }^{\circ} \mathrm{C}$ ), growth of graphitic domains and reduction in surface defects continued. However, the authors observed from FE-TEM images, the graphitic domains had less curvature radius and as a result a reduction in confined space, when the pyrolysis temperature was raised above $1300{ }^{\circ} \mathrm{C}$. This is associated with the increased degree of structural ordering, confirmed by the observed sharper (002) XRD peak which also shifted to higher two Theta angles. Electrochemically, the variation in physical structure resulted in changes to galvanostatic profiles, sodium ion storage specific capacity and diffusivity (Fig. 10a-e). ${ }^{54}$ Fig. 10f clearly shows that as pyrolysis temperature increases the sodium ion storage contributed from the adsorption mechanism decreases, contributed from the intercalation mechanism increases and a maximum capacity of $\sim 160 \mathrm{~mA} \mathrm{~h} \mathrm{~g}^{-1}$ is achieved from the pore-filling mechanism at $1300{ }^{\circ} \mathrm{C}$. The total discharge capacities of the samples are between 210 and $325 \mathrm{~mA} \mathrm{~h} \mathrm{~g}^{-1}$. This was confirmed by a distinct change in sodium-ion diffusivity was observed within this region. ${ }^{56}$ As the voltage drops below $0.1 \mathrm{~V}$, the sodium-ion diffusion coefficient drops significantly, before increasing again as cut-off voltage is reached (Fig. 10a-e insets). According to the authors, the decrease in diffusivity is associated with sodium-ion intercalation within the interlayer spacing of graphitic domains, whilst the increase in diffusivity is due to the pore-filling mechanism. Furthermore, depending on the thermal treatment temperature, the observed point where the diffusion coefficient of sodium-ions changes occurs at different voltages. This suggests, depending on the physical properties of $\mathrm{HC}$, more or less sodium-ion storage contribution from intercalation or pore filling is observed. It seems, for the samples used in this study, an optimal thermal treatment temperature is about $1300{ }^{\circ} \mathrm{C}$ where maximum capacity is obtained particularly in the plateau region. Lastly, by comparing the observed electrochemical results with the physical properties of the HC samples, this study provides strong evidence for the three-stage sodium-ion storage mechanism in HC.

The ${ }^{23} \mathrm{Na}$ magic-angle spinning (MAS) nuclear magnetic resonance (NMR) technique was used to study sodium ion storage mechanism in $\mathrm{HC}$ by Gotoh et al. ${ }^{53}$ Broadening of signals between -9 and $-16 \mathrm{ppm}$ was observed as voltage dropped below $0.1 \mathrm{~V}$ (Fig. 11). A subsequent study confirmed that this signal is attributed to the restricted mobility of sodium ions in nanocavities. The increased broadening being attributed to increased sodium-ion capacity, and variation in state of sodium as a result of heterogeneous distribution of closed pores within HC. ${ }^{57}$ Furthermore, the broadness of the peak also reflects the slow diffusion of sodium ions within the HC microstructure. Meanwhile, the sharper peaks at approximately $10 \mathrm{ppm}$ was assigned to insertion of $\mathrm{Na}$ ions between parallel and near parallel graphene layers. ${ }^{53}$

It is obvious from the above discussion that discrepancy surrounding the correct model of sodium-ion storage relative to

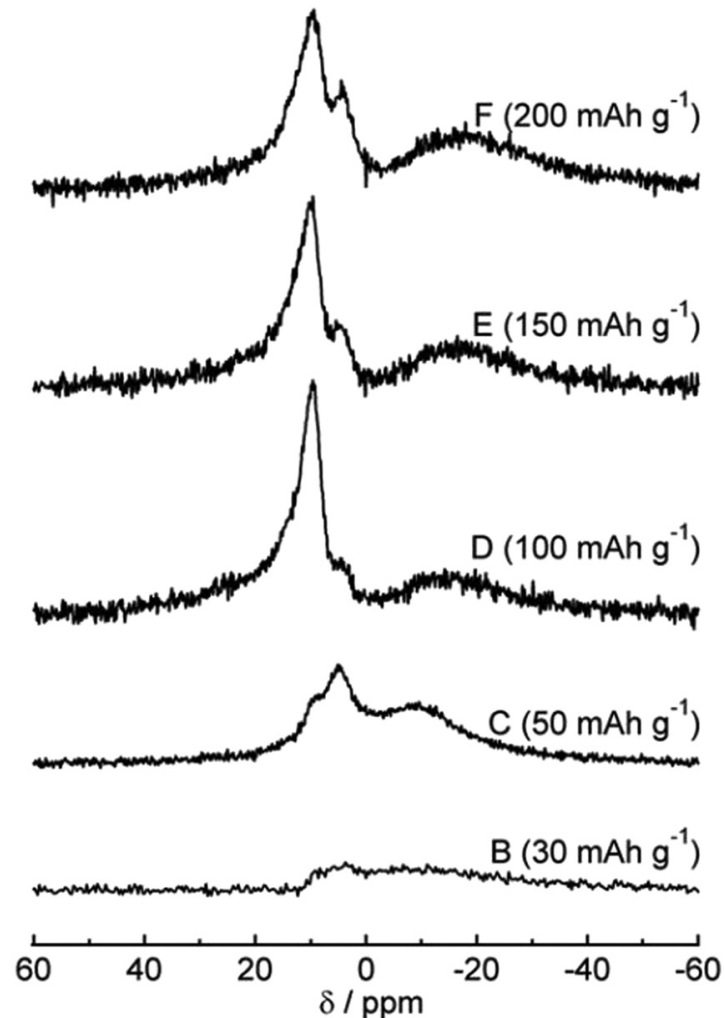

Fig. $11{ }^{23} \mathrm{Na}$ MAS NMR spectra at various states of charge. ${ }^{53}$ Copyright 2013, Elsevier.

the high and low voltage profiles of GCD curves remains. Based on the literature data, it seems the adsorption-intercalationpore filling model is a good representation of sodium-ion storage in HC materials. However, the exact charge storage mechanism responsible for a voltage region remains inconclusive. It does need to be pointed out that the pore-filling mechanism particularly refers to the filling of sodium-ions into closed pores in HC. ${ }^{58}$ The charge storage in open pores is categorised in the adsorption mechanism.

\section{Biomass precursors and processing methods for hard carbon}

Biomass precursors are readily available so cost-effective, and can be categorised as (1) lignocellulosic composite directly obtained from biomass, ${ }^{59,60}$ and (2) individual biopolymer constituents such as cellulose ${ }^{61}$ and lignin. ${ }^{62}$ Lignocellulosic biomass is widely distributed, abundant and easily accessible. ${ }^{63}$ These traits make HC derived from lignocellulose biomass costeffective and appealing to practical applications. Also, to increase the sustainability of battery materials, there has been considerable attention towards HC materials sourced from previously end of life materials, such as agricultural wastes. ${ }^{59,64}$ For example, peanut shell derived HC has been investigated for sodium-ion host materials as approximately six million tonnes of peanut shell waste is produced each year worldwide with limited reusability. ${ }^{60}$ In addition, the peel of 
Table 2 Comparison of biomass-derived HC materials for sodium-ion storage ${ }^{a}$

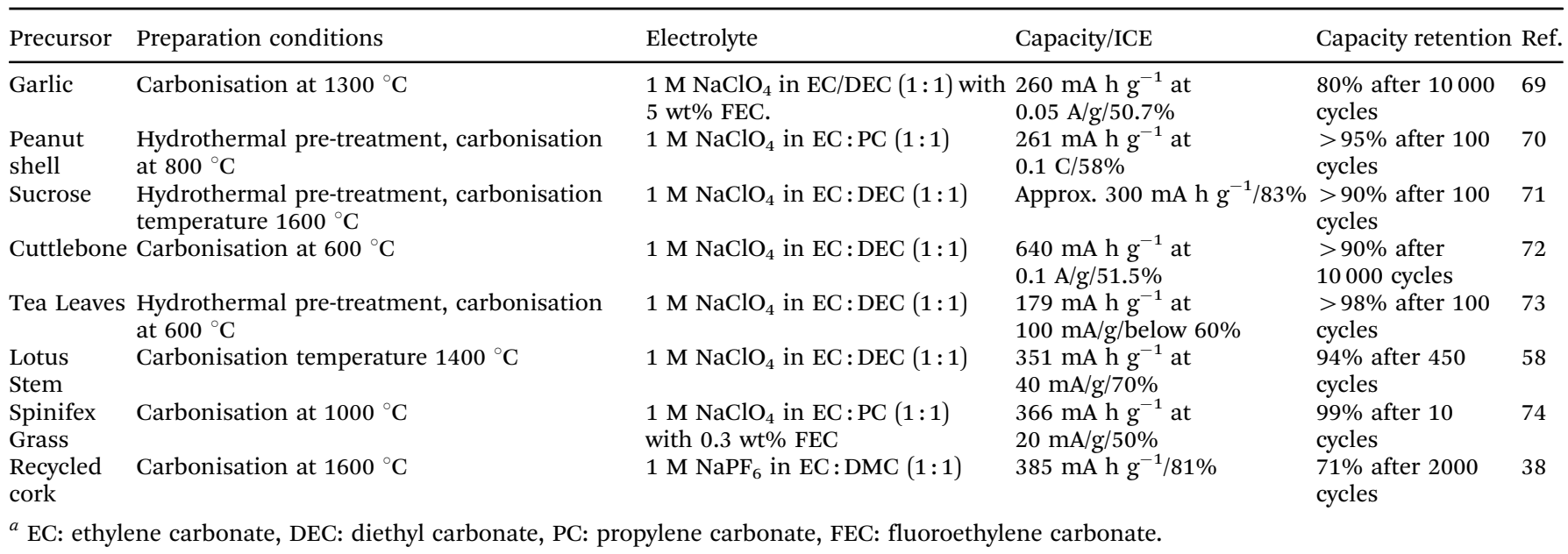

shaddock fruit, a popular fruit consumed in South East Asia, is generally discarded as biodegradable waste following fruit consumption and has also shown positive sodium-ion storage performance following carbonisation. ${ }^{65}$ Due to the abundance and variation in chemical composition of each biomass source, HC materials from different precursors show different electrochemical properties (Table 2). In addition to being cheap and sustainable, the chemical composition along with the macro and micro-architecture associated with variation in biomass can facilitate unique properties. ${ }^{65-67}$ For instance, tamarind is known to hyper accumulate Ca-ions from the soil during growth resulting in Ca-rich organic biomass. ${ }^{68} \mathrm{~A}$ study showed that doping of Ca-ions resulted in $\mathrm{HC}$ with expanded interlayer spacing. The structural change as a result of the Ca doping changed the storage and diffusion of sodium-ions within the
HC. ${ }^{68}$ Therefore, the selection of precursor plays an important role in producing electrode materials with tuneable structural properties in response to desired electrochemical properties.

\subsection{Lignocellulosic biomass}

Lignocellulose is composed of cellulose, hemicellulose, pectin and lignin. The lignocellulosic composition of biomass can vary considerably from source to source. Timbers are composed of up to $50 \mathrm{wt} \%$ cellulose and approximately $25 \%$ of hemicellulose and lignin, respectively. ${ }^{75}$ However, the hemicellulose composition of leaves and grasses range from $50 \%$ to $80 \%$. In addition, nutshells are intermediate between woods and grasses and leaves, with the quantity of lignin and/or pectin ranging between 30 and $40 \%$ and $25-30 \%$ cellulose and hemicellulose, respectively. ${ }^{75}$ What is also interesting is that peanut

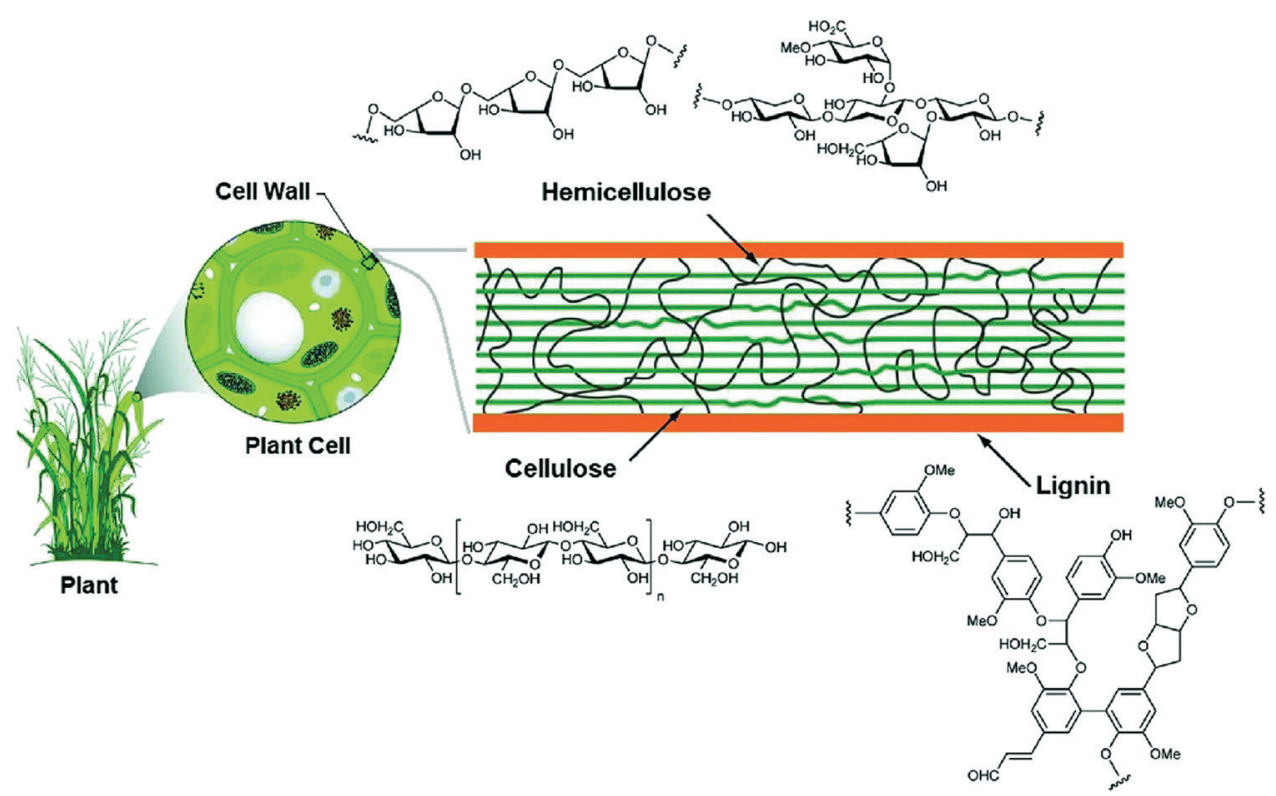

Fig. 12 Lignocellulose composition of plant biomass and the chemical structure of each subunit (cellulose, hemicellulose and lignin). ${ }^{81}$ Copyright 2020 , Springer Nature. 
shells show significant variation in lignocellulose composition between the inner and outer layers. ${ }^{60}$ Furthermore, in comparison to timbers, leaves and grasses and nutshells, fruits have relatively high amounts of pectin. ${ }^{76,77}$ Cellulose, hemicellulose, lignin and pectin are made of different subunits/polymer composition and result in different carbon structures following pyrolysis. ${ }^{78}$ But, variation in lignocellulosic composition can lead to inconsistent physical, chemical and electrochemical properties of biomass-derived HC anode materials in sodiumion energy storage devices. ${ }^{64,79}$

\subsection{Biopolymers \& monomers}

To reduce the impact of compositional variability on the electrochemical performance of biomass-derived HC anode materials, extraction and pyrolysis of individual or tuned combinations of biopolymers has been explored. ${ }^{77}$ Cellulose and hemicellulose are the main structural components of biomass, and its fibrils are bound together by lignin and pectin (Fig. 12). ${ }^{66,80}$ Cellulose is consisted of long chains of D-glucose subunits with $\alpha$-(1,4)-glycosidic linking bonds. In lignocellulose, the long cellulose polymers are reinforced by hemicellulose and lignin. Hemicellulose consists of short monosaccharide units bound together by $\alpha-(1,4)$-glycosidic, and $\alpha$-(1,3)-glycosidic linking groups. Lignin is large and complex, containing three types of phenyl propionic alcohols linked with alkyl-aryl, alkyl-alkyl, and aryl-aryl ether bonds. ${ }^{81}$ The variation in chemical composition of different biopolymers can lead to different carbon microstructures by following high temperature pyrolysis.
Mono- and disaccharides such as glucose $\mathrm{e}^{82,83}$ and sucrose $\mathrm{e}^{84}$ are also frequently studied biomass precursors. ${ }^{71,85}$ Glucose is a six-carbon chain monomer with each carbon bonded to a hydroxyl group. D-Glucose is a cyclic form of glucose consisting of a hemiacetal linkage bond. The high oxygen content of the above-discussed precursor materials is considered one of the main contributors towards the non-graphitisable nature of HC. ${ }^{40}$

\subsection{Processing methods}

3.3.1. Thermal treatment (pyrolysis). During thermal treatment of biomass, dehydrogenation, condensation, hydrogen transfer and isomerisation reactions may take place in a series of stages as temperature increases. ${ }^{86}$ According to Ayhan, ${ }^{87}$ the during pyrolysis, the decomposition of biomass occurs in two stages. The first stage, below $200{ }^{\circ} \mathrm{C}$ is characteristic of slow rate biomass decomposition where elimination of water and formation of surface functionalisation such as carbonyl groups occurs. The second stage above $200{ }^{\circ} \mathrm{C}$ is where decomposition occurs rapidly, leading to the final pyrolysis product. ${ }^{87}$ Typically, the pyrolysis temperature for preparing $\mathrm{HC}$ materials is between 1000 and $2000{ }^{\circ} \mathrm{C}$ (Fig. 13). ${ }^{36,88,89}$ In this temperature range, only partial graphitisation of HC precursors is achieved due to the high concentration of crosslinking $\mathrm{sp}^{3}$ bonded carbons and presence of oxygen heteroatoms. ${ }^{83,84,90,91}$ From current understandings, the strong crosslinking of $\mathrm{sp}^{3}$ bonded carbons lead to the formation of amorphous domains in HC. ${ }^{90}$

3.3.2. Hydrothermal carbonisation. Hydrothermal carbonisation (HTC) has been used as an effective approach to

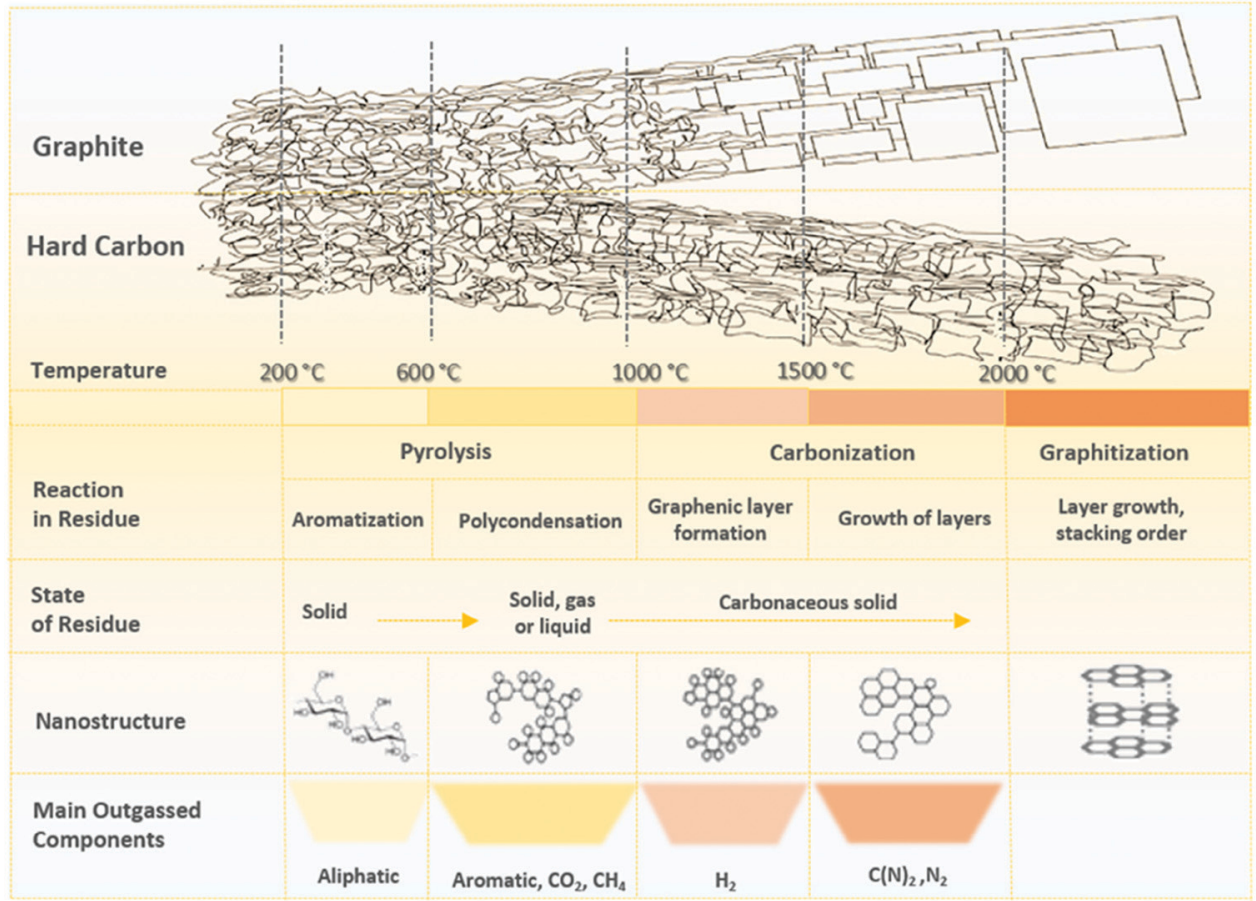

Fig. 13 A schematic illustration representing the changes in chemical and structural characteristics of $\mathrm{HC}$ in response to pyrolysis. ${ }^{86}$ Copyright 2019 , Elsevier. 
(a)
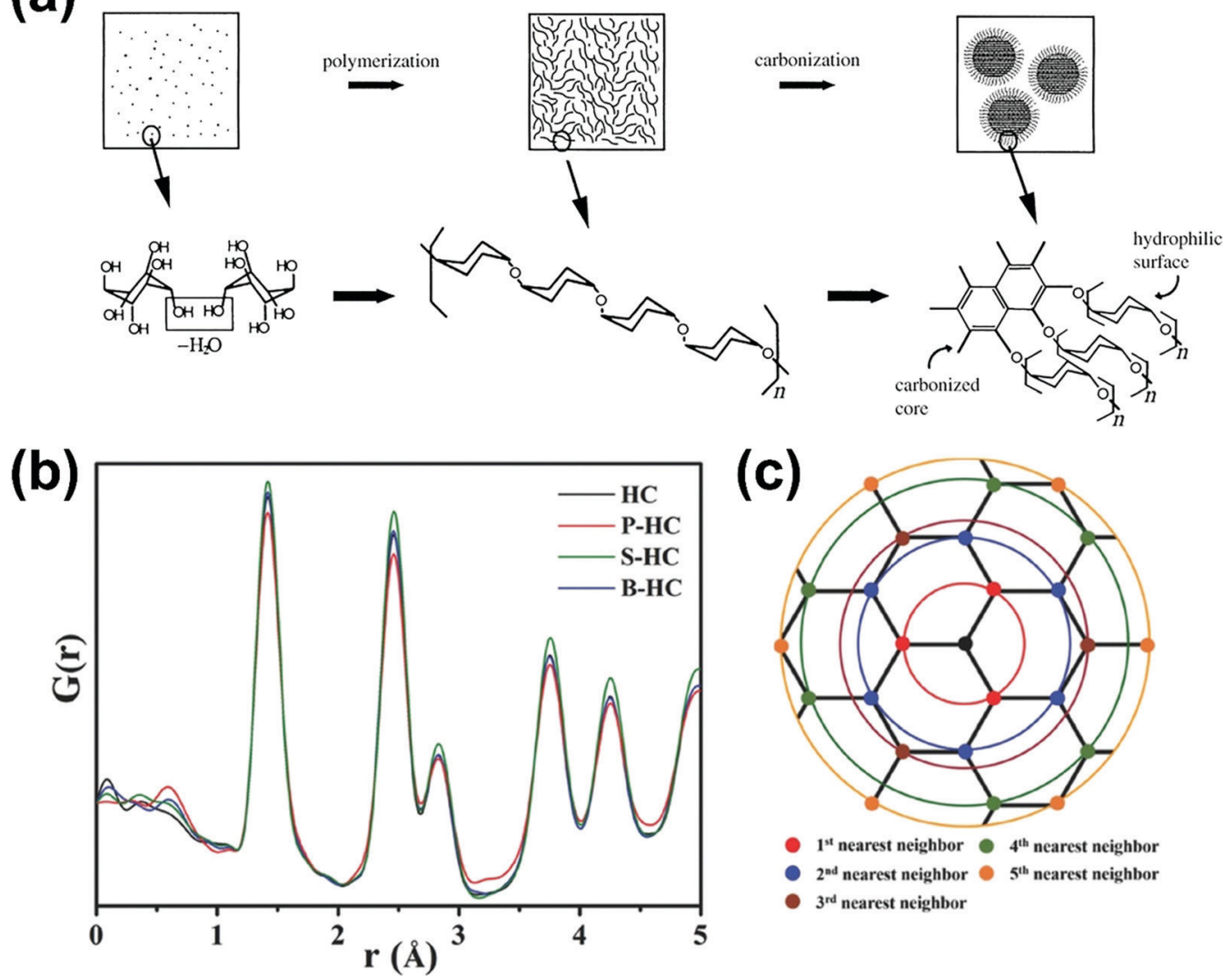

Fig. 14 (a) Hydrothermal reaction mechanism of hard carbon synthesis. ${ }^{96}$ Copyright 2004, Wiley. (b) PDF profiles of heteroatom-doped hard carbon samples and (c) schematic illustration of local structure of graphene to help understand Fig. 14b. ${ }^{83}$ Copyright 2017, Wiley.

preparing carbon materials. ${ }^{88}$ The HTC is based on the naturally occurring "coaling" process where organic matters are chemically carbonised. It has also been used as a pre-treatment method before pyrolysis for the preparation of HC materials. ${ }^{71,73,92}$ Hydrothermal pre-treatment can play an important role in thermochemical processing of carbonaceous electrode materials and is often used to tune the macrostructural ${ }^{93}$ and microstructural ${ }^{73}$ features. ${ }^{94}$ Reaction mechanism illustration has been described in Fig. $14 \mathrm{a} .{ }^{96}$ The hydrothermal pre-treatment of spent tea leaves at $200{ }^{\circ} \mathrm{C}$ for $40 \mathrm{~h}$ in an autoclave followed by pyrolysis at $600{ }^{\circ} \mathrm{C}$ yielded a $\mathrm{HC}$ sample with an expanded $d$-spacing of $0.388 \mathrm{~nm}$, larger than $0.376 \mathrm{~nm}$ of the sample precursor derived HC sample prepared by direct pyrolysis under the same conditions without prior hydrothermal treatment. ${ }^{73}$ In addition, adjusting the HTC treatment parameters is an effective way to control particle size and morphology. ${ }^{95}$ For example, carbon spheres with different diameters can be prepared by adjusting the HTC time, temperature and concentration of the solution. ${ }^{88,96}$ Inorganic species can catalyse the HTC reaction adjusting HC properties. For instance, HTC of rice husk in the presence of iron-ion and iron oxide catalysts resulted in microspherical and rope-like carbon materials, respectively. ${ }^{97}$ When it comes to hydrothermal treatment for complex crude lignocellulosic biomass, the degradation process is more complex due to the interconnected assembly of the individual components requiring a greater activation energy. ${ }^{94}$ Much like the decomposition of lignocellulosic components during high-temperature pyrolysis, the order of susceptibility towards decomposition during HTC follows hemicellulose $>$ cellulose $>$ lignin with hemicellulose and cellulose decomposition starting around $160^{\circ} \mathrm{C}$, and lignin remaining stable at near or above the critical point of water and therefore remains intact. ${ }^{94}$ Therefore, the HTC method can provide a more environmentally friendly approach towards HC synthesis with desired structural characteristics.

3.3.3. Doping of heteroatoms. Heteroatom doping is a material engineering approach that can be used to change the chemical, physical and electrochemical properties of carbon materials. The addition of heteroatoms to carbon materials is often shown to increase the specific capacity and/or rate performance in comparison to non-doped counterparts. ${ }^{98}$ Many studies have investigated heteroatoms such as B, N, O, $\mathrm{S}$ and $\mathrm{P}$ and the underlying changes to defect concentration, electronic conductivity, porosity and graphitic nature of HC materials. ${ }^{99}$ For example, B-doping is known to introduce more in-plane structural defects, S-doping increases the $d$-spacing of the graphitic domains and P-doping affects both defect concentration and graphitic domain $d$-spacing (Fig. 14b) and schematic illustration of local graphene structure shown in Fig. $14 \mathrm{c}^{83,100}$ Also, various oxidation states and interactions 
with doped nitrogen and the carbon matrix can improve the electronic conductivity of the material. ${ }^{36}$

Multi-heteroatom doping of more than one elements has been shown to display synergistic effects on the sodium-ion storage behaviour of HC materials. ${ }^{99}$ Because heteroatoms are present in many biomasses, it is more convenient to prepare heteroatom-containing carbon materials by selecting a precursor which contains the desired heteroatom(s). For example, Mao et al. ${ }^{101}$ used gelatine to prepare porous carbon materials with a high nitrogen content.

In summary, carbonisation methods and material engineering techniques such as surface modification and heteroatom doping can all be used to alter the macro and microstructural properties of $\mathrm{HC}$ in attempts to progress the electrochemical performance of biomass-derived HC as sodium-ion storage host material.

\section{Effect of preparation conditions on hard carbon properties}

\subsection{Effect of thermal treatment on surface properties}

The surface of HC is made up basal and edge graphitic planes scattered with intrinsic vacancy defects and extrinsic surface functional groups. These surface defects alter the chemistry of HC when interacting with sodium-ions, resulting in variation in sodium-ion storage capacity and transport kinetics. ${ }^{102}$ Much like the microstructure, the surface chemistry of biomassderived HC is also dependent on the precursor and processing parameters. A study of Passerini et al. ${ }^{59}$ compared the physical, chemical and electrochemical properties of HC materials derived from apple waste, corncob and peanut shell and carbonised at $1100{ }^{\circ} \mathrm{C}$ for $1 \mathrm{~h}$. According to the X-ray photoelectron spectroscopy (XPS) results, the atomic surface chemical composition varied from sample to sample due to differences in the chemical composition of the biomass precursors. The atomic surface oxygen contents of the carbon samples derived from apple waste, corncob and peanut shell were $6.1,10.3$ and 10.6 at $\%$, respectively. It is also worth mentioning, although the atomic percentage of oxygen is similar for the corncob and peanut shell derived samples, the type of oxygen functional groups differs. The percentages of $\mathrm{O}-\mathrm{H}, \mathrm{O}=\mathrm{C}$ and $\mathrm{O}-\mathrm{C}$ functional groups for the corncob-derived sample were 11.9, 19.4 and 68.2 at\%, respectively, whilst for the peanut shell-derived sample the percentages of these functional groups were 15.6, 39.9 and $54.5 \%$, respectively. ${ }^{59}$ Therefore, the peanut shell derived HC had two times more carbonyl groups in comparison with the corncob-derived HC. According to Liu et al. ${ }^{103} \mathrm{C}=\mathrm{O}$ groups are able to increase the surface wettability of HC towards non-aqueous electrolytes, leading to improved HC electrolyte interactions.

Extrinsic defects such as the above-mentioned oxygencontaining functional groups and the presence of heteroatoms are more sensitive to pyrolysis temperatures. As the pyrolysis temperature was increased from 800 to $1200{ }^{\circ} \mathrm{C}$ the surface oxygen content of sweet gum seed derived HC decreased in the oxygen content according to XPS analysis. ${ }^{104}$ In addition, the distribution of oxygen groups changed from $\mathrm{C}-\mathrm{O}$ to $\mathrm{C}=\mathrm{O}$ with increasing temperature. For example, the at $\%$ of $\mathrm{C}=\mathrm{O}$ increased from $22.95 \%$ to $66.72 \%$ for buckwheat derived $\mathrm{HC}$ as carbonisation temperature was increased from 700 to $1300{ }^{\circ} \mathrm{C} .{ }^{103}$

Other major dopants, which can be introduced by the precursor, or via post treatment, follow the same trend, as the carbonisation temperature increases, the overall dopant content decreases. For example, the nitrogen percentages according to XPS analysis of honey derived HC carbonised at 700, 800 and $900{ }^{\circ} \mathrm{C}$ were $3.57,2.31$ and $1.04 \mathrm{wt} \%$, respectively. ${ }^{105} \mathrm{In}$ addition, the nitrogen functionality also changes in response to increase carbonisation temperature. For instance, when the temperature was increased from 600 to $900{ }^{\circ} \mathrm{C}$ in thermal treatment of nitrogen doped reduced graphene oxide samples, the pyrrolic nitrogen at\% decreased from 3.94 to $1.15 \mathrm{at} \%$, the pyridinic nitrogen content increased from 1.85 to 2.07 at $\%$ whereas the graphitic nitrogen content remained consistent to be around $0.77-0.76$ at\%. According to Yuan et al., thermal treatment creates self-rearrangement of $\mathrm{C}-\mathrm{N}$ bonds, with the pyrrolic $\mathrm{N}$ being less thermally stable resulting in conversion to other forms of $\mathrm{N}-\mathrm{C}$ configurations. ${ }^{105}$ Therefore, as carbonisation temperature increases, the surface nitrogen content decreases in total atomic percentage, and a selfrearrangement of atoms occurs leading to higher content of pyridinic nitrogen and less pyrrolic nitrogen.

Intrinsic defects are also prevalent in HC materials. The Raman spectroscopy technique is often used to characterise intrinsic defective sites in carbon. The D1-band observed through deconvolution of the D-band in Raman spectra represents the presence of intrinsic edge defects on graphene sheets. ${ }^{33,82}$ According to Gomez-Martin et al. ${ }^{106}$ the $I_{\mathrm{D} 1} / I_{\mathrm{G}}$ ratio is indicative of defect concentration of HC. At lower carbonisation temperatures, there is insufficient thermal energy to reduce the defect concentration. For olive pit derived HC samples pyrolysed at temperatures of 800,1000 and $1200{ }^{\circ} \mathrm{C}$, the $I_{\mathrm{D} 1} / I_{\mathrm{G}}$ values were $3.63,3.76$ and 3.58 , respectively. At carbonisation temperatures of 1400,1600 and $2000{ }^{\circ} \mathrm{C}$, the $I_{\mathrm{D} 1} / I_{\mathrm{G}}$ value of the same olive pit derived HC decreased significantly to $2.47,2.49$ and 1.97 , respectively. ${ }^{106}$ This suggests above $1200{ }^{\circ} \mathrm{C}$ the intrinsic defects were significantly removed with increasing carbonisation temperature. It is also important to point out that the concentration of intrinsic defects is proportional to the degree of graphitic organisation of the carbon structure. HC with larger amounts of pseudo-graphitic and graphitic like ordering will have less intrinsic defects than highly disordered HC. ${ }^{107}$ This is also further evidenced by the shaper (002) XRD diffraction peak for samples pyrolysed above $1200{ }^{\circ} \mathrm{C}$ evidencing the higher degree of carbon ordering.

The specific surface area of HC materials varies significantly depending on precursors used and processing conditions. ${ }^{69,84}$ Liu et al. ${ }^{69}$ investigated changes in specific surface area using a garlic precursor in the carbonisation temperature range between 1100 and $1500{ }^{\circ} \mathrm{C}$ and observed a decrease in BET surface area from 196 to $37 \mathrm{~m}^{2} \mathrm{~g}^{-1}$. In comparison, the specific 
surface area of a banana peel derived HC carbonised at $1100{ }^{\circ} \mathrm{C}$ was about $19.3 \mathrm{~m}^{2} \mathrm{~g}^{-1},{ }^{108}$ approximately $175 \mathrm{~m}^{2} \mathrm{~g}^{-1}$ less than the garlic derived $\mathrm{HC}$ carbonised at the same temperature ${ }^{69}$ It is also worth mentioning that the decrease in specific surface area becomes more and more insignificant as carbonisation temperature increases, particularly above $1300{ }^{\circ} \mathrm{C} .{ }^{109}$ Therefore, both carbonisation temperature and precursor selection are important parameters to consider when HC specific surface area is concerned. It is worth pointing out that hightemperature carbonisation is undesired due to decrease in graphitic layer $d$-spacing, as well as an increase in production cost. ${ }^{110}$

\subsection{Effect of thermal treatment on porosity}

Understanding the relationship between electrochemical performance and porous properties (pore size, shape and distribution, and accessibility to charges) is important for future research and development of HC anode materials. ${ }^{50}$ During pyrolysis, the graphitic domains stack one on the other and extend in length and thickness as the carbonisation temperature increases. During this structural rearrangement of the graphitic domains, the electrolyte-accessible (open) and inaccessible (closed) pores are formed (Fig. 15). ${ }^{40}$ It is worth mentioning that the formation of closed pores occurs from overlapping of graphitic crystallites, leading to voids being inaccessible to most probe gas molecules such as nitrogen and helium, as well as electrolyte. ${ }^{111}$

Gomez-Martin and co-workers studied temperature effect on microstructure of olive pit derived HC. ${ }^{106}$ They observed that at low carbonisation temperatures the graphitic domains are randomly orientated with small $L_{\mathrm{a}}$ and $L_{\mathrm{c}}$ values, leading to the formation of a high volume of open pores and low volume of closed pores (Fig. 15a). By analysing the physical adsorption data of $\mathrm{N}_{2}$ and $\mathrm{CO}_{2}$ using the two-dimensional non-local density functional theory (2D-NLDFT) method, the authors found that a $\mathrm{HC}$ sample carbonised at $800{ }^{\circ} \mathrm{C}$ possessed the majority of open pores in the size range between 2 and $3 \mathrm{~nm}$ and 0.35 to $0.6 \mathrm{~nm}$, respectively. By comparing the skeletal density of the sample $\left(1.96 \mathrm{~g} \mathrm{~cm}^{-3}\right)$ with the theoretical density of graphite $\left(2.26 \mathrm{~g} \mathrm{~cm}^{-3}\right)$, it was concluded that this HC had limited closed pore volume. At high carbonisation temperatures, the graphitic domains became better organised with extended $L_{\mathrm{a}}$ and $L_{\mathrm{c}}$ dimensions. This multi-dimensional growth of the graphitic domains led to a reduction in open pore volume and a simultaneous increase in closed pore volume (Fig. 15b). ${ }^{106}$ The open pore of olive pit derived HC increased in size from 4 to $7 \mathrm{~nm}$ when the carbonisation temperature was increased from 800 to $1200{ }^{\circ} \mathrm{C}$. However, negligible ultramicroporosity was realised through $\mathrm{CO}_{2}$ gas adsorption analysis. Interestingly, the true density of the $\mathrm{HC}$ sample carbonised at $1200{ }^{\circ} \mathrm{C}$ decreased significantly to $1.41 \mathrm{~g} \mathrm{~cm}^{-3}$ in comparison with that of the HC sample carbonised at $800{ }^{\circ} \mathrm{C}\left(1.96 \mathrm{~g} \mathrm{~cm}^{-3}\right)$. The lower skeletal density suggests the volume of closed pore increased as carbonisation temperature increased. ${ }^{106}$

Small angle X-ray scattering (SAXS) patterns extracted from synchrotron X-ray analysis showed variation in the broadness of the Q-values as carbonisation temperature increased. ${ }^{112}$ The variation suggests changes in pore size, which is supported by the results from physical adsorption and density measurements. ${ }^{84}$ In comparison to pore size, the total accessible pore volume measured via gas physical adsorption decreased with increasing carbonisation temperature. ${ }^{41,113,114}$ Because closed pores are inaccessible to gases (e.g., helium, nitrogen, argon, and carbon dioxide), a complete understanding of the porosity of $\mathrm{HC}$ needs gas physical adsorption analysis coupled with true density and SAXS measurements. According to Franklin, the near-parallel stacking of the basal planes of graphitic domains combined with the strong crosslinking bonds leads to the formation of fine porous structures of HC. ${ }^{115}$ Therefore, the evolution of porosity of HC in response to increasing pyrolysis temperature occurs through an increase in open pore size, but a decrease in total open-pore volume. For closed pore volume, however, it in general increases from low to intermediate carbonisation temperatures, and then decreases at high carbonisation temperatures (Fig. 16). ${ }^{58}$ Above $1600{ }^{\circ} \mathrm{C}$, the growth and alignment of the graphitic domains begin to reduce the closed pore volume. ${ }^{39}$

\subsection{Effect of thermal treatment on graphitic domains}

From the early work of Stevens and Dahn, ${ }^{42}$ which draws on comparisons between lithium and sodium-ion storage in $\mathrm{HC}$ to more recent studies which tune the HC structure to elucidate the intercalation mechanism, ${ }^{50,84,114}$ sodium-ion storage in HC via the intercalation mechanism into graphitic domains is regarded as a key factor for improving the HC electrochemical performance. This intercalation of sodium ions in graphite
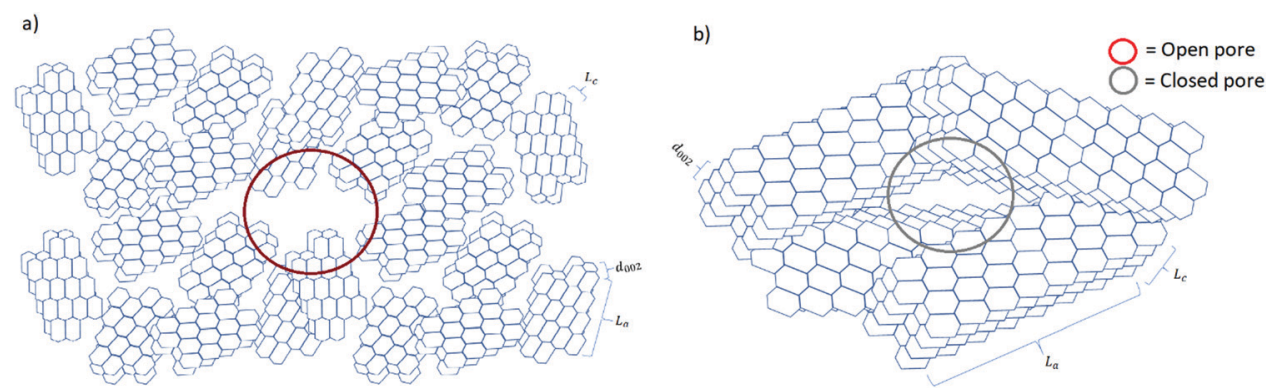

Fig. 15 Schematic comparison of the microstructural features of HC materials prepared at (a) low and (b) high pyrolysis temperatures. 


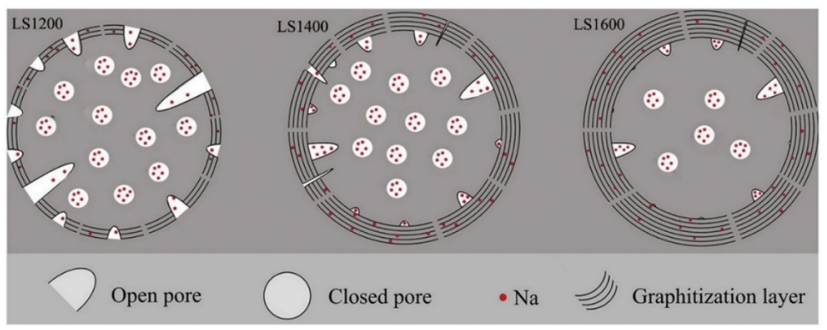

Fig. 16 Illustration of the evolution of porosity as a result of increasing thermal treatment at $1200{ }^{\circ} \mathrm{C}$ (LS1200), $1400{ }^{\circ} \mathrm{C}$ (LS1400) and $1600{ }^{\circ} \mathrm{C}$ (LS1600). ${ }^{58}$ Copyright 2018, Elsevier.

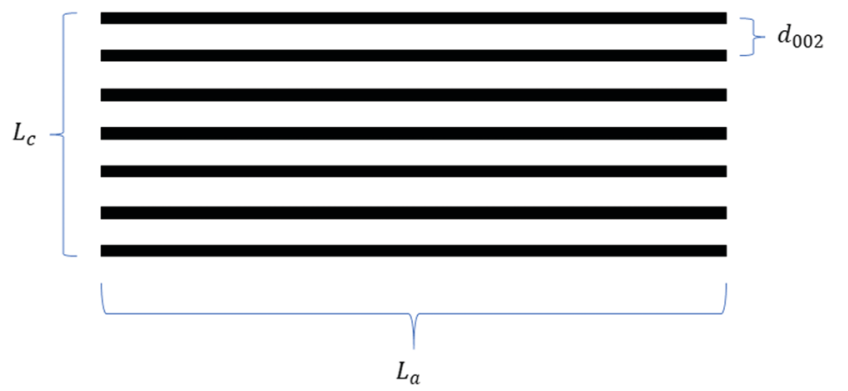

Fig. 17 Schematic showing the three parameters defining a graphitic crystallite.

domains is related to the three defining characteristics as illustrated in Fig. 17, namely the crystallite thickness along the $c$-axis $\left(L_{\mathrm{c}}\right)$, the crystallite width along the $a$-axis $\left(L_{\mathrm{a}}\right)$, and the $d$-spacing between graphene layers $\left(d_{002}\right)$. The evolution of graphitic domains and these defining characteristics during pyrolysis follows a general trend (Fig. 3).

These three parameters define the microstructural features of the graphitic domains within HC materials. ${ }^{114}$ According to Komaba et al., ${ }^{84}$ as carbonisation temperature is increased from 600 to $1200{ }^{\circ} \mathrm{C}$, the crystallite thickness $\left(L_{\mathrm{c}}\right)$ of a sucrose-derived HC remained between 7 and $8 \AA$ as calculated from XRD data. However, as the carbonisation temperature increased above $1200{ }^{\circ} \mathrm{C}$, an increase in crystallite thickness of approximately $1.1 \AA$ for every $100{ }^{\circ} \mathrm{C}$ occurred, up to $2000{ }^{\circ} \mathrm{C} .{ }^{84}$ In addition, the crystallite width $\left(L_{\mathrm{a}}\right)$ also followed a similar trend, albeit slightly more linear growth as a function of increasing carbonisation temperature. ${ }^{114}$ For example, the inplane domain size ( $L_{\mathrm{a}}$ measurement), or the length of the graphitic domain for the sucrose-derived HC samples obtained at pyrolysis temperatures of 900, 1100, 1300, 1600 and $1800{ }^{\circ} \mathrm{C}$ were $14.4,16.5,18.6,23.2$ and $28.0 \AA$ A, respectively. ${ }^{84}$ These results suggest the growth of the graphitic domains along the $a$-axis is at least more energetically favourable in comparison to the growth along the $c$-axis below carbonisation temperatures of $1500{ }^{\circ} \mathrm{C}$. However, growth along both $c$ - and $a$-axes occur rapidly as temperatures exceed $1500{ }^{\circ} \mathrm{C}$.

Studies have shown that there is an inverse relationship between the $d$-spacing and pyrolysis temperature, ${ }^{55,84,116,117}$ especially at high temperatures. It is clearly seen from the XRD patterns of $\mathrm{HC}$ samples pyrolysed at different temperatures in Fig. 18a that as the pyrolysis temperature increased, shift in the (002) peak position to higher degrees two theta occurred, suggesting a gradual decrease in $d$-spacing, particularly at temperatures above $1300{ }^{\circ} \mathrm{C}$ (Fig. 18b). ${ }^{78}$ Fig. 18b also shows that in the pyrolysis temperature range between 1300 and $2000{ }^{\circ} \mathrm{C}$, the graphite crystallite thickness increases as temperature increases.

Therefore, according to current characterisation techniques, as carbonisation temperature increases, the evolution of the graphitic domains increases initially in length $\left(L_{\mathrm{a}}\right)$ of the graphitic domains, followed by simultaneous growth of the crystallite height $\left(L_{\mathrm{c}}\right)$ and reduction in $d$-spacing between graphene layers. Consequently, the number of graphene layers in a single graphite crystallite increase. This can be further validated through the transmission electron microscopy (TEM) images in Fig. 19, which demonstrates the growth in crystallite sizes along both axes as thermal treatment temperature was increased from 700 to $2000{ }^{\circ} \mathrm{C}$. $^{84}$

Franklin ${ }^{115}$ described the graphite crystallite growth phenomenon nicely. The crosslinking of $\mathrm{C}-\mathrm{C}$ bonds and high oxygen-containing groups require sufficient activation energy to infer graphitisation of the amorphous highly disordered carbon domains. The initial orientation of the carbon bonding interactions found in the precursor will therefore play an important role in the evolution of the graphitic domains relative to high-temperature treatment. Ramirez-Martin et $a .^{106}$ used the pair distribution function (PDF) method to analyse the interplanar distance between parallel graphene sheets within the graphitic domains of olive pit derived HC (Fig. 20a). PDF is a powerful technique to characterise the microstructure of materials with limited crystalline ordering. According to this study, little variation of in-plane atomic ordering $\left(d_{100}\right)$ of the carbon framework was observed as the thermal treatment temperature was increased (Fig. 20b). Moreover, the $d_{100}$ values remained very close to the in-place atomic arrangement of graphene (2.132 $\AA$ ). The $d$-layer spacing $\left(d_{002}\right)$ in comparison increased from 3.67 to $3.8 \AA$, as the carbonisation temperature increases up to $1400{ }^{\circ} \mathrm{C}$. However, the $d$-spacing then decreases to $3.72 \AA$ as the pyrolysis temperature is increased up to $2000{ }^{\circ} \mathrm{C}$ (Fig. 20c). ${ }^{106}$ Additionally, there is a clear relationship observed between annealing temperature and crystallite size complementary to the TEM findings in Fig. 20d. In addition, out of plane atomic displacement parameter was generated and a linear relationship with annealing temperature was observed (Fig. 20e). According to the author's interpretation, this is due to the increased contraction of $d$-spacing and simultaneous formation of nanopores as annealing temperature is increased. ${ }^{106}$

\section{Property-performance relationship}

HC properties discussed in Section 4 are very much interlinked in response to precursors and processing conditions. This brings about difficulties in optimising $\mathrm{HC}$ materials for sodium-ion storage because a trade-off is often required. For 

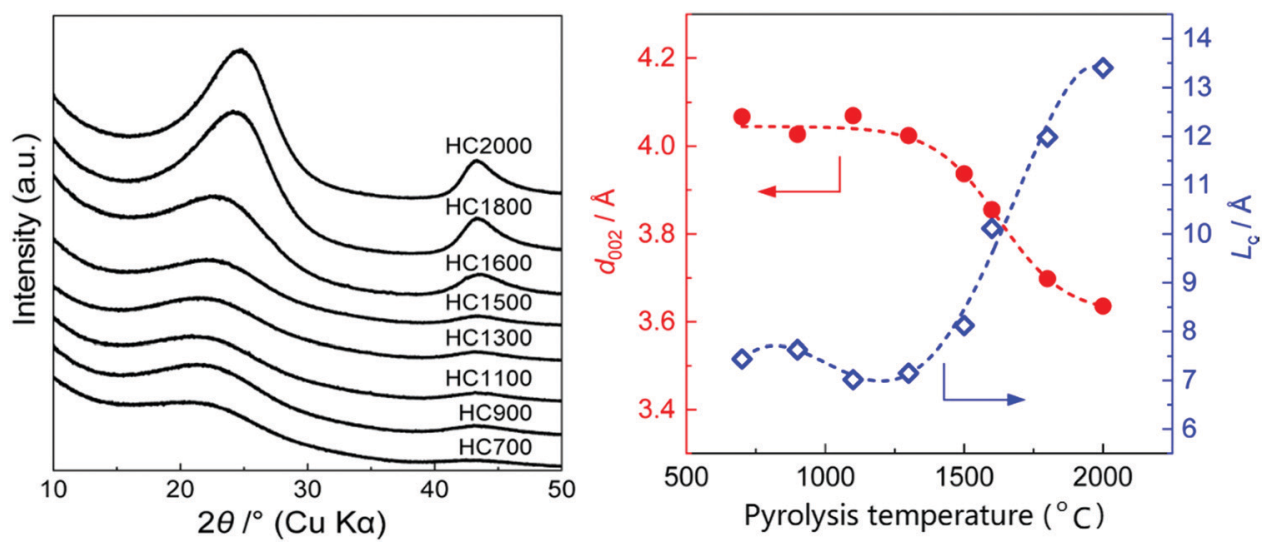

Fig. 18 (a) XRD patterns of sucrose-derived $\mathrm{HC}$ samples pyrolysed at temperatures between 700 and $2000{ }^{\circ} \mathrm{C}$, and (b) relationship between $d$-spacing and graphitic crystallite length along the $c$-axis as a function of pyrolysis temperature. ${ }^{84}$ Copyright 2020 , American Chemical Society.
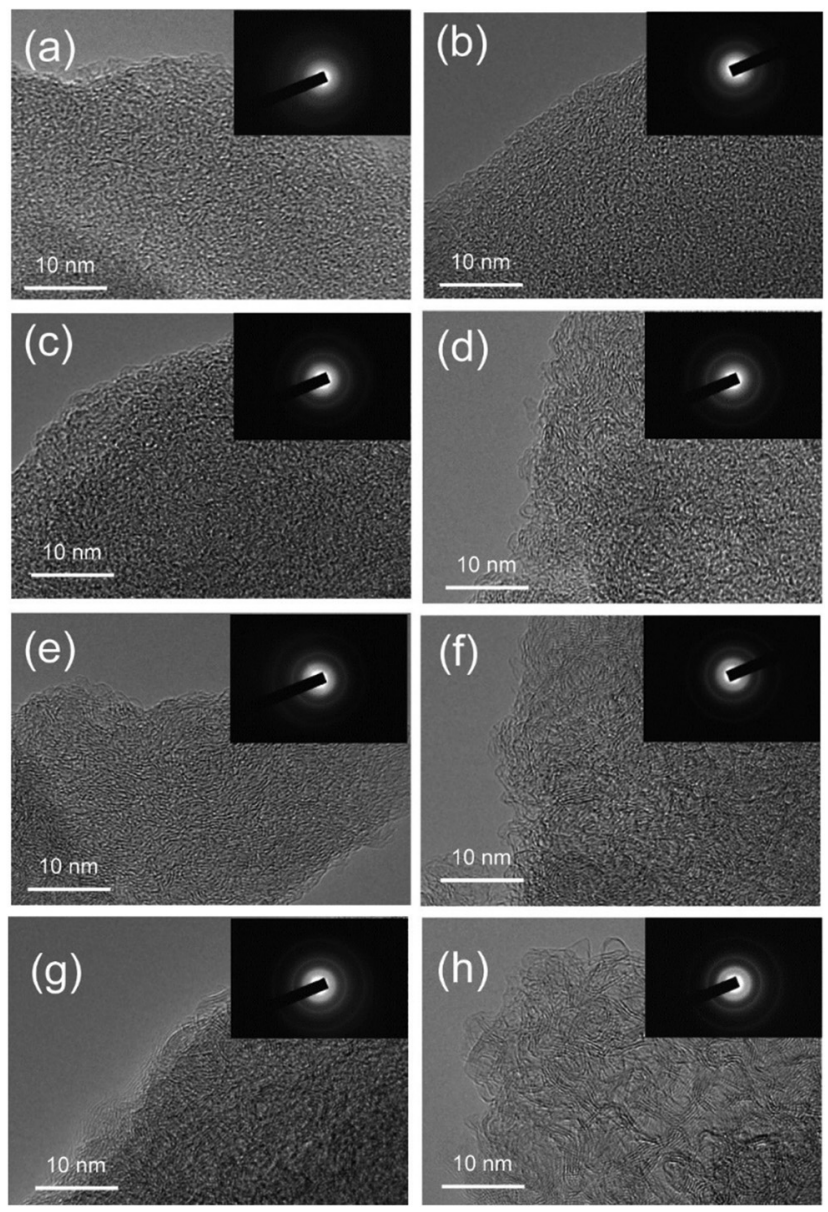

Fig. 19 TEM images showing the crystallite size of sucrose-derived $\mathrm{HC}$ samples pyrolysed at (a) 700, (b) 900, (c) 1100, (d) 1300, (e) 1500, (f) 1600 (g) 1800 , and (h) $2000{ }^{\circ} \mathrm{C}^{84}$ Copyright 2020 , American Chemical Society

example, low specific surface area HCs typically obtained from high-temperature pyrolysis excel in coulombic efficiency and reversible capacity performance. However, the decreased surface area and pore size with increasing pyrolysis temperatures are unfavourable for sodium-ion transport, especially at high charge/discharge currents. For this reason, it is crucial to understand the relationship between HC properties and electrochemical performance especially regarding what macro and microstructural features contribute to an observed performance behaviour. There is currently a great deal of research interest and activity aiming to engineer biomass-derived HC materials for improving NIB performance. This section will provide an evaluation of the macro and microstructural properties of $\mathrm{HC}$ and their underlying electrochemical performance relationships. Furthermore, it is important to note, the relationship reported in the literature between certain structural properties and pyrolysis temperature is not definite.

\subsection{Defects and surface functionalization-performance relationship}

Due to the disordered microstructure of HC, the concentration of surface defects is high. The D-band peak observed in Raman spectroscopy at a Raman shift of approximately $1400 \mathrm{~cm}^{-1}$ is indicative of the concentration of various types of defect. ${ }^{118}$ For $\mathrm{HC}$, the D-band Raman intensity is significantly larger in comparison to graphite for example which has a higher degree of $\mathrm{sp}^{2}$ ordering and negligible surface defects. ${ }^{119}$ The presence of defects contribute to the interaction between electrode surface and electrolyte, playing an important role in electrochemical performance. ${ }^{120}$ The electrode/electrolyte interface influences the coulombic efficiency, charge storage capacity, rate performance and electrochemical stability of HC anodes. ${ }^{121}$ Intrinsic defects and extrinsic surface functionalities are two important factors determining the surface properties of HC materials.

As mentioned, the surface of carbon materials are intrinsically made of basal and edge planes. ${ }^{122}$ Basal planes make up the most significant portion of the total surface area, but have negligible electrochemical activity towards sodium ions. ${ }^{123,124}$ Edge planes on the other hand, refer to the active surface which plays a decisive role in the electrochemical activity of $\mathrm{HC}$ materials. ${ }^{50,124}$ Intrinsic edge defects in $\mathrm{HC}$ are formed in response to distortions or loss of carbon atoms within the extended carbon matrix. ${ }^{82,125}$ Distortions and removal of 

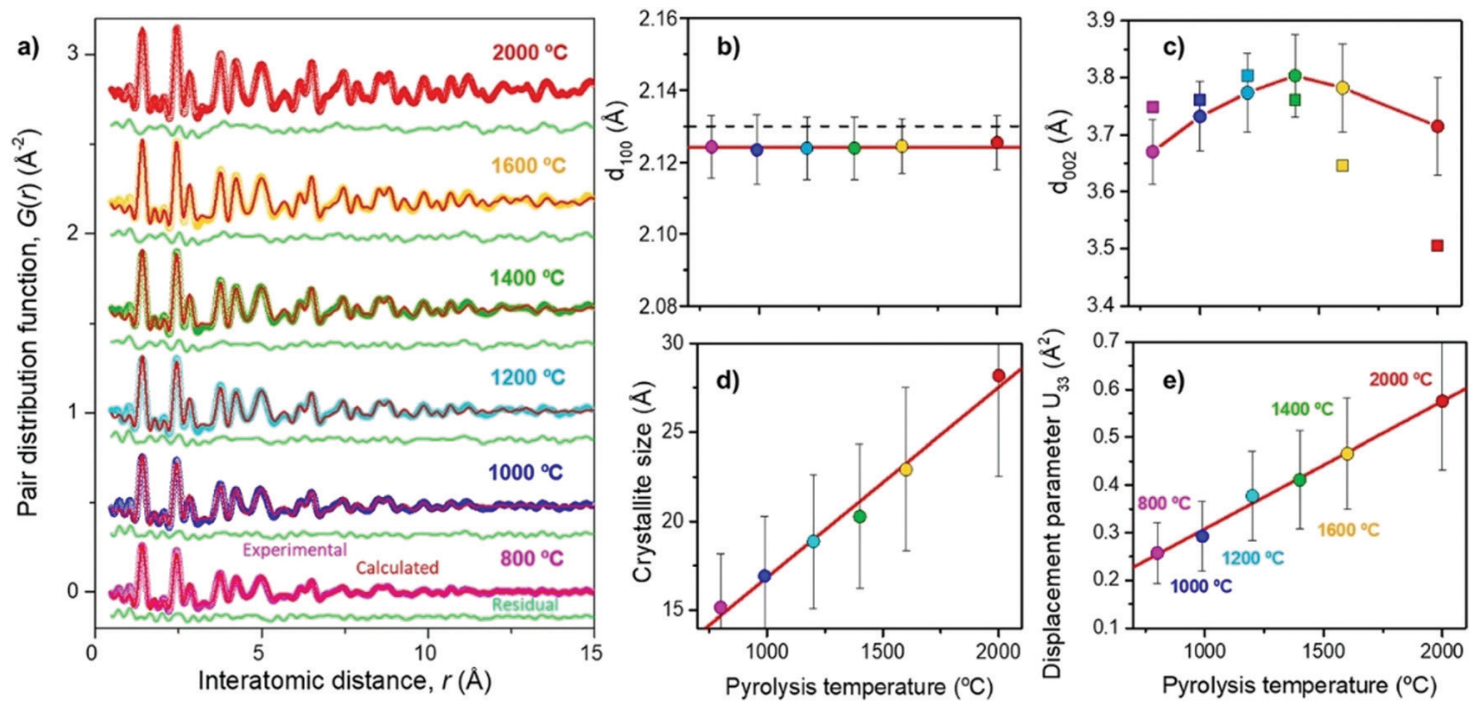

Fig. 20 (a) Experimental (coloured) and calculated using the pairs distribution function method (red), (b) $d_{100}$ spacing, (c) $d_{002}$ spacing, (d) crystallite size, and (e) out-of-place displacement parameter of $d$-spacing of olive pit derived HC samples prepared at temperatures ranging from 800 to $2000{ }^{\circ} \mathrm{C} .106$ Copyright 2019, American Chemical Society.

carbon atoms within the matrix lead to Stones-Wales defects, monovacancies, divacancies and edge defects in the $\mathrm{HC}$ framework..$^{82}$ DFT calculations suggest because of the disruption to the local electron density, the introduction of vacancy defects in HC increases the sodium-ion adsorption energy. ${ }^{126}$ According to Guo et al. ${ }^{82}$ the adsorption energies of sodiumions on the surface of pristine, mono-, and divacancy defective sites in graphene were $0.22,-0.58$ and $-1.01 \mathrm{eV}$, respectively. The more negative adsorption energies are suggestive of more favourable for sodium-ion adsorption for both mono- and divacancy defects (Fig. 21). This is due to the ability of the defect sites to accumulate electron charge density. Similarly, Singh et al., ${ }^{127}$ observed stronger adsorption energies of sodium-ions on the surface of double-vacancy graphene in comparison to pristine graphene. However, It was also accompanied by an increase in sodium-ion migration activation barrier by approximately $0.4 \mathrm{eV} \cdot{ }^{126}$ Furthermore, Xiao et al. ${ }^{32}$ report the strong binding interaction between sodium-ions and intrinsic defect location caused a sodium-ion trapping effect, with the trapped ion then creating a repulsive electric field. What this led to was reduced theoretical sodium-ion capacity. Therefore, the intrinsic defects may increase the sodium-ion storage capacity, but the stronger binding interaction can decrease migration of sodium-ions and lead to loss in reversible capacity and reduced sodium ion diffusion. It is worth pointing out that these observations are based upon single sodium-ion interactions only. When subsequent sodium-ions are introduced into the system, the binding energies between the defect site and sodium-ion can decrease. ${ }^{127}$

The loss in reversible capacity is partially due to the trapping of sodium-ions at defective sites. ${ }^{32,50,128,129}$ Xiao et al. ${ }^{32}$ prepared low-defect sucrose derived $\mathrm{HC}$ samples at pyrolysis temperature of $1300{ }^{\circ} \mathrm{C}$ with different heating rates and observed a superior ICE for the sample carbonised at the slowest heating rate, namely $0.5{ }^{\circ} \mathrm{C} \mathrm{min}^{-1}$. The authors attributed the increase in ICE to the reduction in intrinsic surface (a)

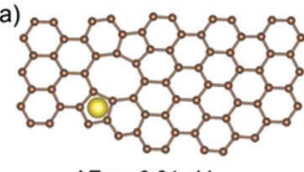

$\Delta \mathrm{Ea}=-0.81 \mathrm{eV}$

type1

(b)

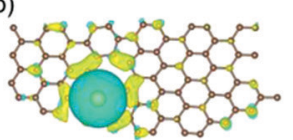

(c)

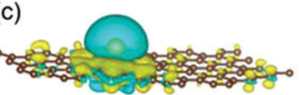

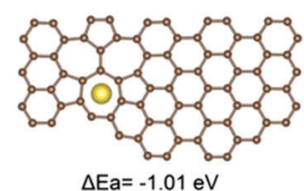

type2
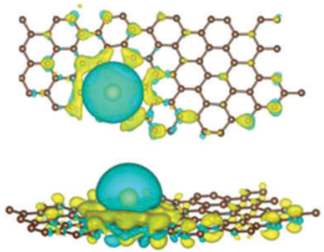

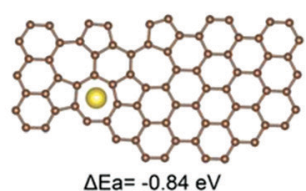

type3
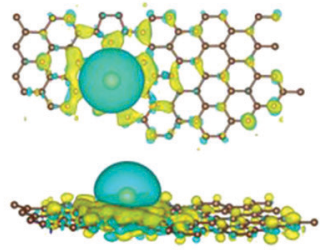

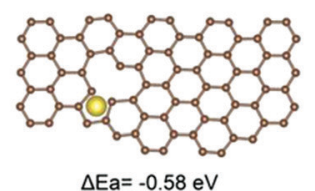

type 4
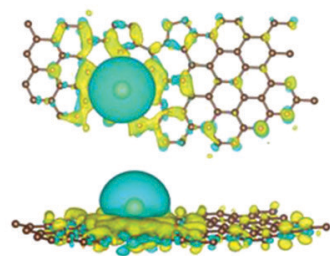

Fig. 21 Computational simulations of sodium-ion adsorbed on di-vacancy defects of Types 1-3 and single-vacancy defects of Type 4 in HC viewed from top ( $a$ and b) and side (c). ${ }^{82}$ Copyright 2020, Wiley. 
a)

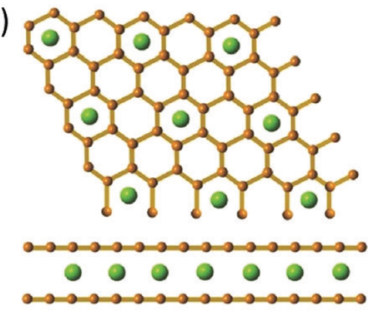

b)

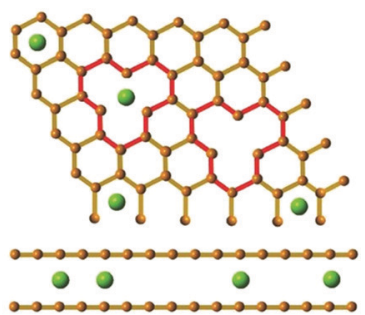

Fig. 22 Illustration of $\mathrm{Na}$-ion storage formulation between (a) pristine graphite and (b) vacancy-defective graphite. ${ }^{32}$ Copyright 2018, Wiley.

defects as a result of using a slower heating rate during pyrolysis. ${ }^{32}$ In addition, through theoretical analysis the authors found that the strong interaction between sodium ions and defects created a dual trapping and repulsive effect, suggesting a more sparse accumulation of cations in the graphene lattice occurs in the presence of basal defects compared with pristine graphite (Fig. 22). ${ }^{32}$

Much like intrinsic surface defects, extrinsic defects such as surface heteroatom functional groups also influence the surface chemistry of HC to a large extent. ${ }^{130}$ Doping of heteroatoms such as nitrogen, boron, sulphur, fluorine and phosphorus can be used to create surface functionalities. These dopants can be added singularly or multiply to the HC material to obtain certain cumulative contributions. Depending on the heteroatom/s used, doping of HC occurs via heteroatom substitution of carbon atoms by elements such as nitrogen ${ }^{131,132}$ and boron ${ }^{133}$ or surface transfer doping by sulphur, ${ }^{134,135}$ fluorine ${ }^{136}$ and phosphorus ${ }^{137}$ between the carbon layers. Substitution doping agents lead to a change in disruption of the localised electron density whilst the surface transfer dopants can lead to enlarged interlayer spacings and geometric distortion. ${ }^{138}$ Therefore, due to the sluggish kinetics of sodium-ion transport typically observed in the bulk of HC, heteroatom doping has been explored to improve the rate capability and capacity of HC through increasing the surfaceactive sites and adjusting the internal microstructure of HC. ${ }^{102}$

Disruption to local electron density caused by the substitution of carbon atoms with nitrogen or boron heteroatoms, is thought to provide additional electrochemical reactivity and surface wettability towards electrolytes. ${ }^{125}$ These improved properties are a result of several structural and electrochemical changes to the HC surface. For example, the larger electronegativity of nitrogen in comparison to carbon creates polarisation in the carbon matrix and improves electron-accepting properties. ${ }^{102}$ Ideal for the attraction of sodium-ions.

Nitrogen commonly adopts one of the following three bonding configurations within the carbon matrix: (1) pyrrolic nitrogen where nitrogen adopts a position in a five membered ring with nitrogen situated in the position open to the monovacancy, (2) pyridinic nitrogen where the nitrogen adopts a position in a six membered ring with nitrogen situated in the position open to the vacancy defect, and (3) quaternary or graphitic nitrogen where nitrogen adopts a position in a six membered ring without any surrounding vacancies (Fig. 23). ${ }^{125,138}$

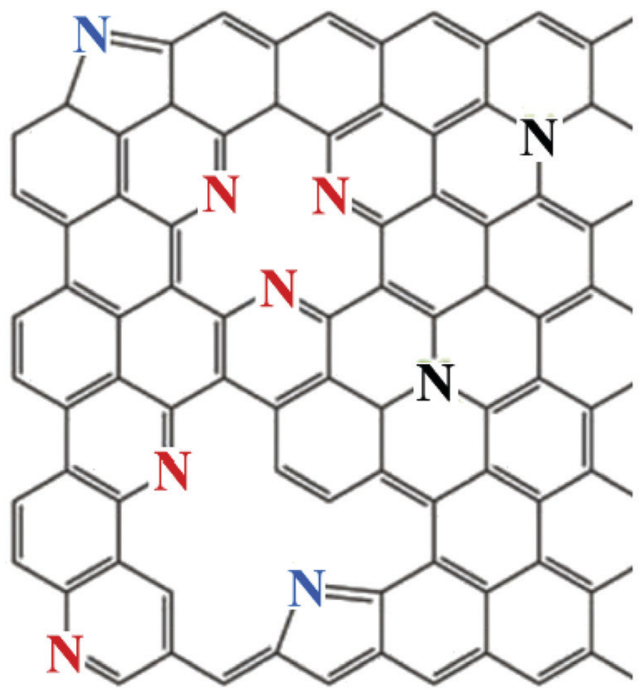

N: Graphitic, N: Pyridinic, N: Pyrrolic

Fig. 23 The various nitrogen configurations within a carbon framework. ${ }^{139}$ Copyright 2018, Elsevier.

Due to the proximity of the pyrrolic and pyridinic nitrogen to the defective sites, local electron resonance is destabilised. Conversely, the $2 \mathrm{~s}^{2}$ and $2 \mathrm{p}^{3}$ valence electrons for nitrogen are stabilised in graphitic nitrogen due to the uninterrupted local $\pi$-orbital resonance. ${ }^{140}$ According to DFT calculations, pyrrolic, pyridinic and graphitic nitrogen doped HCs have lower energy barriers in comparison to pristine graphene towards sodiumion diffusion. This suggests nitrogen doping can increase the ionic conductivity of $\mathrm{HC}$, thus promoting the diffusion of sodium-ions within the HC matrix. Interestingly, the diffusion of sodium-ions in pyrrolic and pyridinic nitrogen doped HC is towards the nitrogen and defective locations, whereas for the graphitic nitrogen-doped system the sodium-ions migrate away from the doped site. ${ }^{138}$ Therefore, theoretically pyrrolic, pyridinic and graphitic nitrogen doping is considered to influence the ionic conductivity with pyrrolic and pyridinic also influencing the chemical reactivity of HC surfaces.

It has been experimentally observed that nitrogen doping leads to mixed electrochemical results with the major challenge being the ability to tune the configuration of the nitrogen, in favour of high content of pyridinic and/or pyrrolic nitrogen species. ${ }^{141}$ However, studies which have been able to achieve high pyridinic and/or pyrrolic nitrogen-doped HC have shown positive results for sodium-ion storage and diffusion properties. ${ }^{142}$ For example, Longan shell derived HC samples with in situ doped nitrogen thermally treated at 600, 700,800 and $850{ }^{\circ} \mathrm{C}$ showed slight variation in nitrogen content according to elemental and XPS analysis. However, closer analysis of the N 1s XPS spectra indicated the sample carbonised at $800{ }^{\circ} \mathrm{C}$ had the highest content of pyridinic nitrogen. In addition, the HC sample with higher pyridinic nitrogen had superior capacity, rate performance and cycling stability at $5 \mathrm{~A} \mathrm{~g}^{-1} \cdot{ }^{142}$ Thus, it is not just the presence of heteroatoms, but also the configuration of the heteroatoms within the carbon matrix that 
influences electrochemical performance. It is also important to understand, the greater surface area could also be contributing to these results.

Unlike nitrogen, boron is an electron-deficient doping agent in comparison to carbon. As such it can alter the electrochemical properties of $\mathrm{HC}$ materials in different ways. According to Qiu et al., ${ }^{133}$ the electron-deficient state of boron readily accepts electrons from the carbon framework, leading to a shift in Fermi level and an increase in electrical conductivity. In addition, boron dopants typically introduce vacancy defects into adjacent locations thus providing additional conductivity. ${ }^{120}$ However, to the best of our knowledge limited research has been conducted on boron doped-biomass derived HC for sodium-ion storage.

Sulphur, fluorine and phosphorus are all interstitial doping elements due to atomic size difference. The presence of these doping elements distorts the carbon matrix and increases the $d$-spacing of graphitic domains. A computational study showed single-atom doping of fluorine ${ }^{136}$ and phosphorus ${ }^{143}$ into pseudo-graphitic layers increased the interlayer distance by 0.3 and $0.4 \AA$, respectively. Experimentally, using phosphorus doping to increase the interlayer spacing from 3.79 to $3.86 \AA$ led to reversible capacity enhancement from 283 to $359 \mathrm{~mA} \mathrm{~h} \mathrm{~g}^{-1}$ at $20 \mathrm{~mA} \mathrm{~g}{ }^{-1}{ }^{144}$ Nevertheless, much like intrinsic defects, the stronger binding presence of particular heteroatom defects have been associated with sodium-ion trapping and contribute to low reversible sodium-ion capacity. ${ }^{30,137}$

\subsection{Open porosity-performance relationship}

The open pores in HC can influence sodium-ion charge storage capacity and diffusion kinetics. ${ }^{38,145,146}$ Because open pores are accessible to most inert gases via physical adsorption, as well as electrolyte, the external specific surface area of HC reflects its open porosity. For example, Ding et al. ${ }^{48}$ used the air activation method to control the open porosity and external specific surface area of peat moss derived HC. It was found that the open pore volume of $\mathrm{HC}$ samples carbonised at $900{ }^{\circ} \mathrm{C}$ with and without air activation was 0.059 to $0.21 \mathrm{~cm}^{3} \mathrm{~g}^{-1}$, respectively. Moreover, the specific surface area also increased from 45.1 to $271.2 \mathrm{~m}^{2} \mathrm{~g}^{-1}$. Therefore, larger open pore volume results in greater specific surface area of HC. In addition, the size or diameter of open pores within $\mathrm{HC}$ also effects the specific surface area. HC with larger volume of micropores, $(<2 \mathrm{~nm}$ in diameter) has a larger surface area than $\mathrm{HC}$ with the same total open pore volume but mesoporous in size $(>2 \mathrm{~nm}) \cdot{ }^{145}$ Therefore, much of the external surface area is attributed to the open porosity of $\mathrm{HC}$, and should be used interchangeably. Also, because the defects discussed in Section 5.1 are located on the surface, the more porous a HC material is, the larger it's specific surface area and subsequently number of defects will be. These are all important considerations when analysing the electrochemical properties of HC. As for the observed electrochemical performance of the air-activated and non-activated samples, Ding et $a .^{48}$ reported at a current density of $50 \mathrm{~mA} \mathrm{~g}^{-1}$, the sodium-ion storage capacities at the tenth cycle was 150 and $100 \mathrm{~mA} \mathrm{~h} \mathrm{~g}{ }^{-1}$, respectively. The increased capacity for the activated sample was also associated with the sloping region of the GCD profile due to related surface adsorption storage mechanism. This suggests that the open pores/specific surface area combine to contribute towards capacitive-like sodium-ion storage. Also, because the $I_{\mathrm{G}} / I_{\mathrm{D}}$ ratio was similar for both samples, the greater capacity is attributed to the greater open porosity and external surface area.

One issue with large open pore volume and high specific surface area of $\mathrm{HC}$ materials is their low initial coulombic efficiency (ICE) ${ }^{30,147,148}$ which in part is due to the formation of SEI and trapping of sodium-ions at defective sites. The formation of the SEI layer occurs at the electrode surface and is due to the decomposition of electrolyte during cycling at voltages outside the electrochemical stability window of the electrolyte. ${ }^{30}$ Through elemental analysis using the XPS technique, $\mathrm{Na}_{2} \mathrm{CO}_{3}$ and $\mathrm{NaF}$ were observed in the SEI layer. ${ }^{149}$ This confirms that sodium-ions are consumed during the formation of the SEI layer. ${ }^{149-151}$ In a full cell device, sodium-ions are supplied by the cathode, therefore, any loss of active sodiumions would decrease the capacity of the device. ${ }^{129}$ By reducing the surface area of a sorghum stalk waste-derived HC from 234.5 to $35.55 \mathrm{~m}^{2} \mathrm{~g}^{-1}$ The ICE was increased from $57.5 \%$ to $62.2 \%$. According to Luo et al., ${ }^{150}$ lowering the specific surface area of $\mathrm{HC}$ is a common strategy for improving the ICE of HC anodes, ${ }^{152}$ but it is generally associated with a reduction in rate performance. ${ }^{153}$

In addition, Olsson et al. ${ }^{154}$ experimentally and theoretically investigated the effect of surface defects and their location on the formation of the SEI layer. They found that oxygen functionalities on the basal defects led to the formation of inorganic SEI compounds and immobilisation of sodium-ions. In comparison, oxygen functionalities on the edge defects were identified as energetically favourable sites towards reversible storage of sodium ions. Therefore, any undesirable consumption of sodium-ions during the formation of the SEI layer will reduce the reversible capacity of the electrode.

Another approach to improve reversible capacity is to modify HC by adding an artificial SEI layer on electrode surface, which is usually carbon based. Carbon coating can be achieved using various methods. ${ }^{155}$ Zhang et al. ${ }^{128}$ prepared carbon-coated HC spheres via mixing of polypropylene with glucose before pyrolysis. The thickness of the coated carbon layer can be controlled by adjusting experimental parameters, such as deposition time, gaseous flow rate and concentration of coating agent. Adding an additive to the electrolyte is another efficient approach to enhance reversible capacity. Fluoroethylene carbonate (FEC) is a commonly used additive, which changes the composition of the SEI layer. Fondard et al. ${ }^{151}$ added $3 \mathrm{wt} \%$ FEC to a $1 \mathrm{M}$ sodium hexafluorophosphate $\left(\mathrm{NaPF}_{6}\right) /$ ethyl carbonate:dimethyl carbonate (EC:DMC in 1:1) electrolyte and observed significantly more NaF formation and a decrease in $\mathrm{Na}_{2} \mathrm{CO}_{3}$ compared to electrolyte without FEC. ${ }^{151}$ Therefore, many factors in addition to the electrode material itself are important to consider when improving the electrochemical performance of HC materials.

\subsection{Closed porosity-performance relationship}

The performance contribution of closed pores in HC materials towards sodium-ion storage has gained a great deal of 
interest. ${ }^{39,100,112,128}$ This is driven by the observed direct relationship between closed pore volume and sodium-ion storage performance. Li et al., ${ }^{38}$ quantified the closed pore volume of cork-waste derived HC samples pyrolysed at different temperatures in the range between 800 and $1600{ }^{\circ} \mathrm{C}$. The sample pyrolysed at $1600{ }^{\circ} \mathrm{C}$ exhibited the highest closed pore volume $\left(0.29 \mathrm{~cm}^{3} \mathrm{~g}^{-1}\right)$ and largest specific capacity contribution below

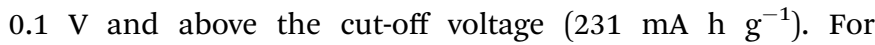
comparison, the sample pyrolysed at $1400{ }^{\circ} \mathrm{C}$ with the second highest closed pore volume of $0.19 \mathrm{~cm}^{3} \mathrm{~g}^{-1}$ achieved a specific capacity contribution of $189 \mathrm{~mA} \mathrm{~h} \mathrm{~g}^{-1}$ in the same potential window. Lee et al. ${ }^{39}$ reported that the bulk densities of coffee waste derived HC samples carbonised at 1600, 2000, 2400 and $2800{ }^{\circ} \mathrm{C}$ were $1.56,1.38,1.42$ and $1.45 \mathrm{~g} \mathrm{~cm}^{-3}$, respectively. According to the authors, the variation in bulk density of the HC samples allowed for quantifiable evidence for the increase in closed pore volume. The authors observed that the second cycle discharge capacity in the plateau region of the sample carbonised at $2000{ }^{\circ} \mathrm{C}$ with the lowest bulk density was approximately $235 \mathrm{~mA} \mathrm{~h} \mathrm{~g}^{-1}$, which is over two times higher than that of the sample carbonised at $1600{ }^{\circ} \mathrm{C}\left(100 \mathrm{~mA} \mathrm{~h} \mathrm{~g}^{-1}\right)$. Moreover, the sample carbonised at $2000{ }^{\circ} \mathrm{C}$ displayed the higher ICE of $90.4 \%$. Therefore, the authors concluded that a lower bulk density, suggestive of greater closed pore volume, of HC is favourable for sodium-ion storage in the low-voltage plateau region. ${ }^{39}$ Zhang et al. ${ }^{128}$ used an open pore closing strategy by depositing polypropylene on the surface of glucose derived HC. With this strategy, the authors were able to alter the true density, and the closed porosity of HC. The sample with the lowest true density $\left(1.8 \mathrm{~g} \mathrm{~cm}^{-3}\right)$ exhibited the highest plateau capacity of $220 \mathrm{~mA} \mathrm{~h} \mathrm{~g}^{-1}$. For comparison, other samples with true densities of 2.01, 2.02 and 2.33 displayed plateau capacities of 185,160 and $165 \mathrm{~mA} \mathrm{~h} \mathrm{~g}{ }^{-1}$, respectively. ${ }^{128}$ The authors concluded that the plateau capacity is crucial to achieving high energy density of HC-based NIB cells. Therefore, closed pore and performance relationship deserves extensive research efforts. $^{58}$

In regard to sodium-ion storage mechanism in closed pores, it is believed that sodium ions diffuse through the spaces of parallelly and near-parallelly stacked graphitic domains. ${ }^{39}$ During this process, the sodium ion becomes de-solvated at the HC electrode/electrolyte interface. ${ }^{150,156}$ As a result, electrolyte decomposition is minimised, this significantly improving sodium-ion reversibility and coulombic efficiency. Kano et al. ${ }^{157}$ prepared $\mathrm{HC}$ materials with different closed pore volumes and observed a linear relationship between closed pore volume and reversible capacity (Fig. 24a). The GCD discharge profile shown in Fig. 24b represents an optimised HC sample with high volume of closed pores, and a highly reversible extended plateau capacity. Therefore, the storage of sodium-ions in closed pores appears to result in highly reversible capacity and cycling capabilities. It can be concluded that increasing closed pore volume increases reversible sodium ion storage capacity, thus enhancing NIB cell performance.

\subsection{Graphitic domains-performance relationship}

As discussed in Section 4.3, the graphitic domains of HC prepared at low pyrolysis temperatures (generally below $\left.1200{ }^{\circ} \mathrm{C}\right)$ are typically smaller in size $\left(L_{\mathrm{c}}\right.$ and $\left.L_{\mathrm{a}}\right)$ with a larger $d$-spacing. Increasing the pyrolysis temperature $\left(>1200{ }^{\circ} \mathrm{C}\right)$ results in a graphitic domain growth and a reduction in the $d$-spacing. ${ }^{84}$ Moreover, the various graphitic domain assemblies within HC materials alter the associated sodium-ion storage performance. For this reason, it is critical to understand the role of the graphitic domains, including $d$-spacing and crystallite size on the sodium-ion storage performance.

Firstly, theoretical studies have shown that $d$-spacing becomes energetically favourable towards sodium-ion intercalation when greater than $0.37 \mathrm{~nm} .{ }^{49,158}$ Below $0.37 \mathrm{~nm}$, the energy barrier for sodium-ion intercalation becomes significantly large to overcome, as evidenced from the limited sodium-ion storage capacity of graphite which has a $d$-spacing of $0.335 \mathrm{~nm}$. Experimentally, Sun et al. ${ }^{107}$ observed a decrease in $d$-spacing from 0.385 to $0.337 \mathrm{~nm}$, as well as a drop in plateau capacity from $192.5 \mathrm{~mA} \mathrm{~h} \mathrm{~g}^{-1}$ to $115.2 \mathrm{~mA} \mathrm{~h} \mathrm{~g}^{-1}$, when the pyrolysis temperature was increased from 1300 to $1500{ }^{\circ} \mathrm{C}$ for Ginko leaf derived HC. Furthermore, the theoretical energy cost of sodium-ion inserted between two graphene layers drops to $0 \mathrm{eV}$ when the $d$-spacing becomes $0.4 \mathrm{~nm}$ or larger. ${ }^{159}$ According to Sun et al. ${ }^{107}$ this implies the larger $d$-spacing of $0.4 \mathrm{~nm}$ or more results in surface-like pseudo-adsorption of sodium-ion, and not intercalation. Which as mentioned previously is not ideal due to the
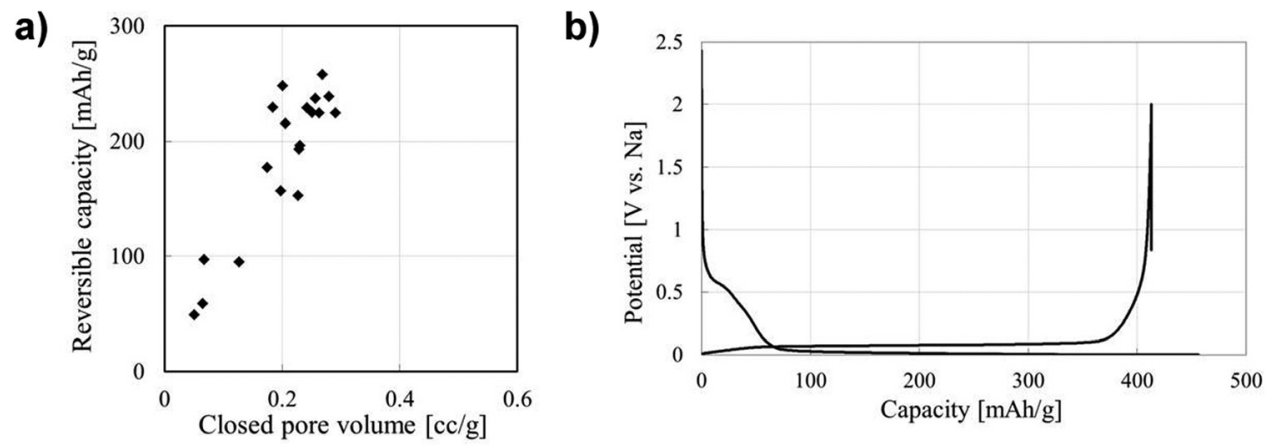

Fig. 24 (a) Correlation between closed pore volume and reversible capacity of sucrose derived HC. (b) GCD profile for sucrose derived $\mathrm{HC}{ }^{157}$ Copyright 2015, IOPscience. 

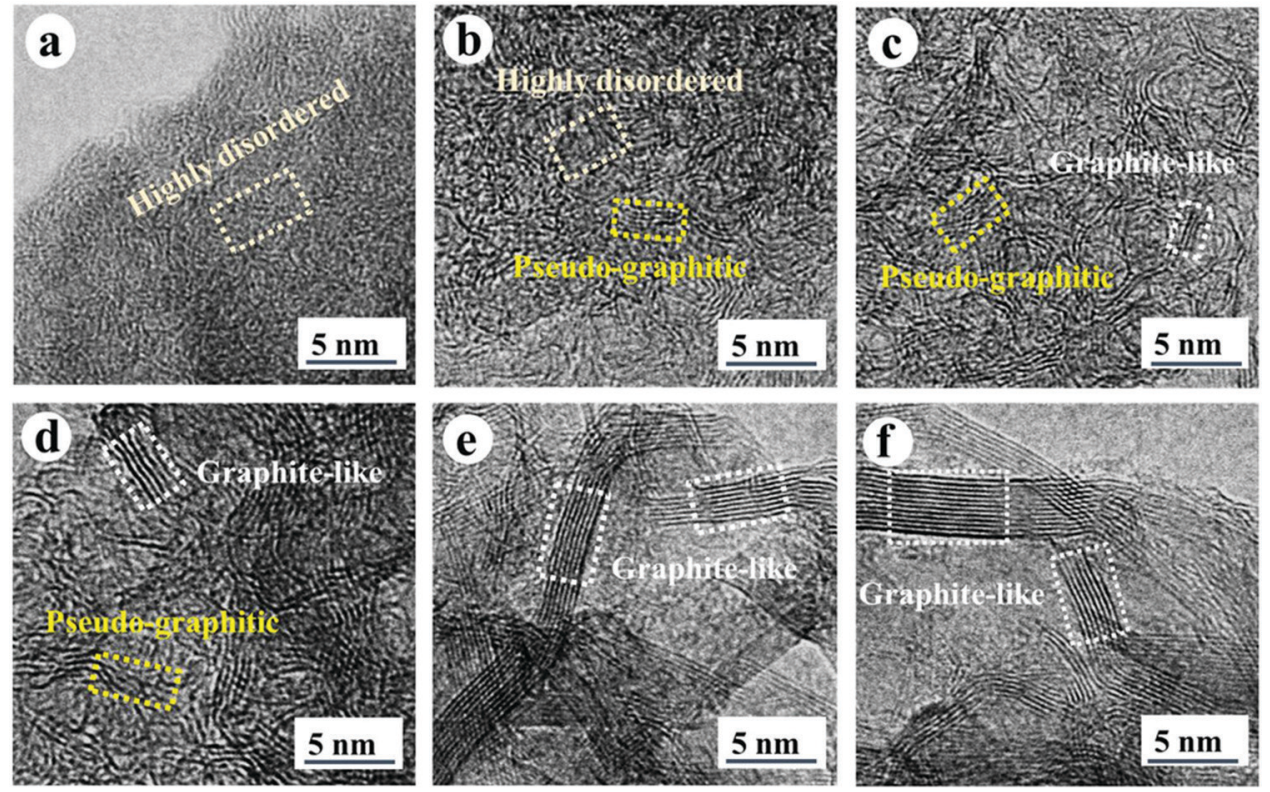

Fig. 25 High resolution transmission electron microscopy (HRTEM) images of HC samples pyrolysed at (a) 600, (b) 1000, (c) 1300, (d) 1700, (e) 2000 and (f) $2500{ }^{\circ} \mathrm{C}^{107}$ Copyright 2019 , Wiley.

increased unwanted side reactions between electrolyte and electrode surface. In addition, the rate of sodium-ion diffusion between the parallel graphene layers in graphitic domains is dependent on the $d$-spacing. ${ }^{158}$ Computational calculations showed that the energy migration barrier for sodium ions decrease linearly as a function of $d$-spacing between 0.35 and $0.50 \mathrm{~nm} .{ }^{158}$ This was also experimentally confirmed. ${ }^{107,158}$ Therefore, the interlayer spacing between graphene planes should be larger than $0.37 \mathrm{~nm}$, but less than $0.4 \mathrm{~nm}$ to ensure adequate intercalation and diffusion of sodium-ions within the graphitic domains of HC.
Secondly, satisfactory formation of the graphitic crystallites must be achieved to provide sufficient levels of sodium-ion intercalation storage sites. Depending on the precursor and preparation conditions, HC can have various degrees of crystallographic ordering of the $L_{\mathrm{c}}$ and $L_{\mathrm{a}}$ dimensions. Generally, the graphitic crystallites of $\mathrm{HC}$ vary from highly disordered at low pyrolysis temperatures, to pseudo-graphitic at intermediate pyrolysis temperatures, and graphite-like at high temperatures (Fig. 25). ${ }^{107} \mathrm{HC}$ with a large quantity of highly disordered carbon domains lacks of $L_{\mathrm{c}}$ and $L_{\mathrm{a}}$ ordering. This results in randomly orientated disordered graphene planes with enlarged
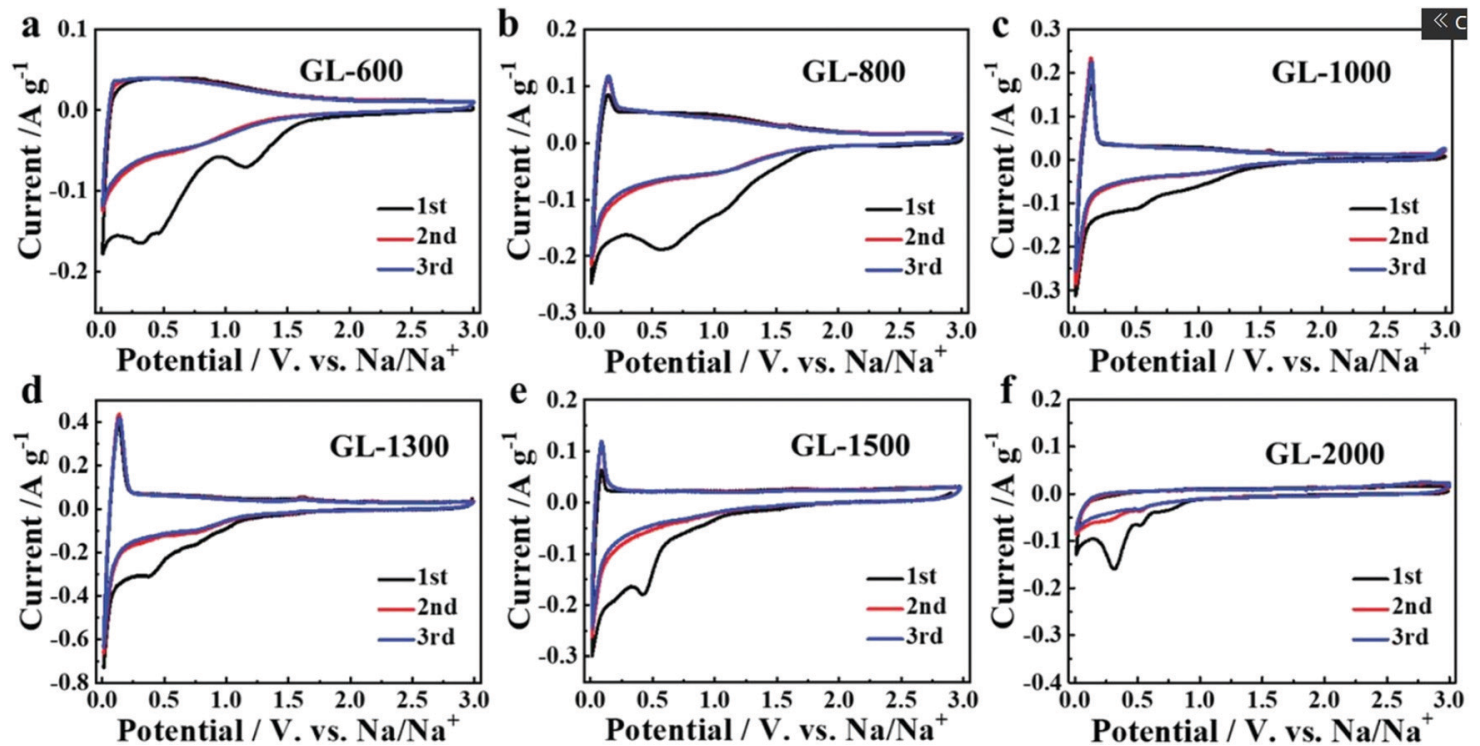

Fig. 26 CVs of HC samples pyrolysed at (a) 600, (b) 800, (c) 1000, (d) 1300, (e) 1500 and (f) $2000{ }^{\circ} \mathrm{C}^{107}$ Copyright 2019, Wiley. 

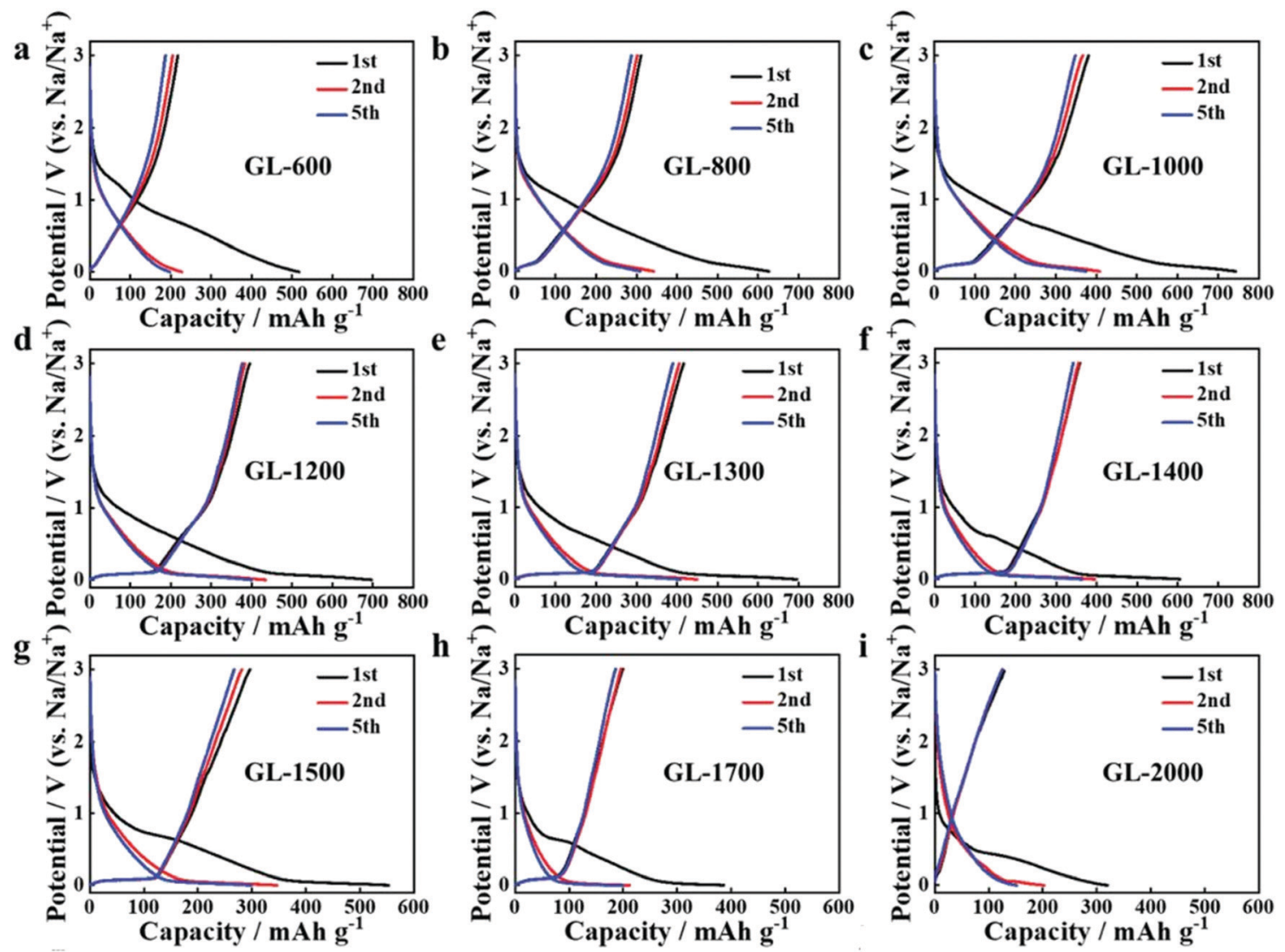

Fig. 27 GCD profiles of $\mathrm{HC}$ samples pyrolysed at (a) 600 , (b) 800 , (c) 1000 , (d) 1200 , (e) 1300 and (f) $1400{ }^{\circ} \mathrm{C}$, (g) 1500 , (h) 1700 and (i) $2000{ }^{\circ} \mathrm{C} \cdot{ }^{107}$ Copyright 2019, Wiley.

$d$-spacings greater than $0.4 \mathrm{~nm} .{ }^{107}$ As mentioned, a $d$-spacing larger than $0.4 \mathrm{~nm}$ is not suitable for sodium-ion intercalation and results in reduced diffusion-like sodium-ion storage. As pyrolysis temperature was increased, the $\mathrm{HC}$ microstructure rearranged, forming pseudo-graphitic domains with reduced $d$-spacing typically between $0.36-0.40 \mathrm{~nm} .{ }^{107}$ This $d$-spacing range is large enough for favourable sodium-ion insertion, whilst being narrow enough to reduce unwanted sodium-ion surface adsorption contributions. This is evidenced by the transition from pseudo-capacitive to diffusion-like storage behaviour observed from the cyclic voltammograms (CV) (Fig. 26) and GCD curves (Fig. 27) for HC when treated at intermediate pyrolysis temperatures between 1000 and $1700{ }^{\circ} \mathrm{C}$. In addition, the change to more pseudo-graphitic domains corresponds to an increase in reversibility of sodium-ion storage. For example, the reversible capacity of a $\mathrm{HC}$ samples pyrolysed at 600 and $1300{ }^{\circ} \mathrm{C}$ were approximately $200 \mathrm{~mA} \mathrm{~h} \mathrm{~g}$ and $400 \mathrm{~mA} \mathrm{~h} \mathrm{~g}{ }^{-1}$, respectively. ${ }^{107}$

At very high pyrolysis temperatures, typically above $2000{ }^{\circ} \mathrm{C}$, HC materials have a high degree of structural ordering due to the formation of graphite-like domains. In this circumstance, the $d$-spacing becomes very narrow, thus unfavourable for sodium-ion intercalation. The ability of the HC materials to retain capacity at high current densities suggests sodium-ion storage is dominated by the surface adsorption mechanism. ${ }^{107}$
Therefore, HC with a high concentration of pseudo-graphitic domains with $d$-spacing between approximately 0.37 and $0.40 \mathrm{~nm}$ is considered optimal for reversible sodium-ion storage, with the upper limit being more favourable towards sodium-ion kinetics.

\section{Conclusion and perspectives}

Firstly, it is important to address resource sustainability in developing rechargeable batteries. Biomass-derived hard carbon, in particular the biomass precursor is obtained from naturally abundant non-competing sources, is a sustainable electrode material for energy storage.

Secondly, a complete understanding of the sodium-ion storage mechanism is required to direct the tailoring and tuning of biomass-derived hard carbon anode materials for sodium-ion storage. There is still under intense debate regarding sodium-ion storage mechanisms in hard carbon. Because low-voltage plateau capacity with high reversibility and stability against cycling is most desirable for improving cell performance, it is important to validate the exact sodium ion storage mechanism in this plateau region. Fundamental studies using in situ physical and electrochemical characterisation techniques combined with computational means to elucidate 
sodium-ion storage mechanisms in hard carbon are needed to boost the sodium-ion-based energy storage technology.

Thirdly, and very much linked to the first point, the complicate physical and chemical properties of hard carbon materials derived from different biomass precursors and prepared using various methods under different conditions have resulted in difficulty in assessing the role of key parameters of the hard carbon in sodium ion storage, such as $d$-spacing and close pore volume. The importance of accurately quantifying the $d$-spacing of the graphitic microcrystallites is evident. By doing this, a greater understanding of the sodium-ion storage capacity and diffusion will assist in progressing this field. Pair distribution function is an innovative characterisation technique which could assist in providing reliable interpretation of the microstructural traits of biomass-derived hard carbon. Measurement of true density using the helium pycnometer method provides additional means to characterise closed pores.

Fourthly, the low initial coulombic efficiency typically observed from biomass-derived hard carbon anode materials is a critical issue that needs to be addressed. Side reactions occurring between electrolyte and hard carbon electrode surface, as well as trapping of sodium ions at defective sites are the main contributing factors associated with the low initial coulombic efficiency. To combat the performance-inhibiting factors attributed to low initial coulombic efficiency, innovative synthesis and advanced engineering techniques need to be further explored and developed. In addition, surface engineering such as coating of biomass-derived hard carbon has also shown promising results concerning increasing the reversible capacity. In addition to the development of advanced biomassderived hard carbon anode materials, the electrolyte including the salts, solvents and additives deserves extensive research efforts in future development.

Achieving a greater understanding of points 1-3 above should then provide a roadmap for further preparation methods aimed to enhance the electrochemical performance of hard carbon materials. Experimenting with pre- and post-carbonisation techniques, in addition to carbonisation temperature, time and heating rates of various biomass precursors with the desired microstructural characteristics in mind, should provide hard carbon materials with enhanced electrochemical results.

As a final statement, it is worth mentioning that addressing the above recommendations will improve the electrochemical performance of hard carbon. However, for practical applications, each component of a battery cell, such as the cathode, the electrolyte, the separator and the current collector, must be optimised.

\section{Conflicts of interest}

The authors declare no conflict of interest.

\section{Acknowledgements}

Professor X. S. Zhao is the recipient of an Australian Research Council Australian Laureate Fellowship (project number
FL170100101) funded by the Australian Government. This research was partially funded by the Australian Government through the Australian Research Council (project number DP200102573).

\section{Notes and references}

1 G. Blanco, R. Gerlagh, S. Suh, A. Ahenkorah, J. Barrett, H. De Coninck, M. Diaz, R. Mathur, N. Nakicenovic, J. Pan, H. Pathak, J. Rice, R. Richels, S. Smith, D. Stern, F. Toth, P. Shou, M. Gomes and A. Verbruggen, Climate Change 2014 Mitigation of Climate Change - Chapter 4, 2014.

2 United Nations, About the Sustainable Development Goals, https:/www.un.org/sustainabledevelopment/sustainabledevelopment-goals/, accessed 6 September 2020.

3 J. Hewson, W. Steffen, L. Hughes and M. Meinshausen, AUSTRALIA'S PARIS AGREEMENT PATHWAYS: UPDATING THE CLIMATE CHANGE AUTHORITY'S 2014 EMISSIONS REDUCTION TARGETS, 2021.

4 T. Perveen, M. Siddiq, N. Shahzad, R. Ihsan, A. Ahmad and M. I. Shahzad, Renewable Sustainable Energy Rev., 2020, 119, 109549.

5 A. Ponrouch and M. R. Palacín, Philos. Trans. R. Soc., A, 2019, 377, 20180297.

6 A. Valero, A. Valero, G. Calvo and A. Ortego, Renewable Sustainable Energy Rev., 2018, 93, 178-200.

7 K. Turcheniuk, D. Bondarev, V. Singhal and G. Yushin, Nature, 2018, 559, 467-470.

8 A. Noori, M. F. El-Kady, M. S. Rahmanifar, R. B. Kaner and M. F. Mousavi, Chem. Soc. Rev., 2019, 48, 1272-1341.

9 T. A. Faunce, J. Prest, D. Su, S. J. Hearne and F. Iacopi, MRS Energy Sustainable, 2018, 5, 10.

$10 \mathrm{~T}$. B. Lee, The story of cheaper batteries, from smartphones to Teslas, https://arstechnica.com/tech-policy/2020/09/thestory-of-cheaper-batteries-from-smartphones-to-teslas/.

11 P. K. Nayak, L. Yang, W. Brehm and P. Adelhelm, Angew. Chem., Int. Ed., 2018, 57, 102-120.

12 M.-S. Balogun, Y. Luo, W. Qiu, P. Liu and Y. Tong, Carbon, 2016, 98, 162-178.

13 C. Vaalma, D. Buchholz, M. Weil and S. Passerini, Nat. Rev. Mater., 2018, 3, 1-11.

14 A. Ponrouch, R. Dedryvère, D. Monti, A. E. Demet, J. M. Ateba Mba, L. Croguennec, C. Masquelier, P. Johansson and M. R. Palacín, Energy Environ. Sci., 2013, 6, 2361-2369.

15 H. Pan, Y.-S. Hu and L. Chen, Energy Environ. Sci., 2013, 6, 2338-2360.

16 M. Okoshi, Y. Yamada, A. Yamada and H. Nakai, J. Electrochem. Soc., 2013, 160, 2160-2165.

17 Y.-S. Hu and Y. Lu, ACS Energy Lett., 2019, 4, 2689-2690.

18 E. De La Llave, V. Borgel, E. Zinigrad, F. F. Chesneau, P. Hartmann, Y. K. Sun and D. Aurbach, Isr. J. Chem., 2015, 55, 1260-1274.

19 B. Xiao, T. Rojo and X. Li, ChemSusChem, 2019, 12, 133-144. 
20 A. Ponrouch, D. Monti, A. Boschin, B. Steen, P. Johansson and M. R. Palacín, J. Mater. Chem. A, 2015, 3, 22-42.

21 E. Irisarri, A. Ponrouch and M. R. Palacin, J. Electrochem. Soc., 2015, 162, 2476-2482.

22 S. Alvin, H. S. Cahyadi, J. Hwang, W. Chang, S. K. Kwak and J. Kim, Adv. Energy Mater., 2020, 10, 2000283.

23 Z. Xu, J. Park, G. Yoon, H. Kim and K. Kang, Small Methods, 2019, 3, 1800323.

24 Z. Wang, S. M. Selbach and T. Grande, RSC Adv., 2014, 4, 4069-4079.

25 R. M. N. M. Rathnayake, T. T. Duignan, D. J. Searles and X. S. Zhao, Phys. Chem. Chem. Phys., 2021, 23, 3063-3070.

26 B. Jache and P. Adelhelm, Angew. Chem., Int. Ed., 2014, 53, 10169-10173.

27 M. Wahid, D. Puthusseri, Y. Gawli, N. Sharma and S. Ogale, ChemSusChem, 2018, 11, 506-526.

28 W. Wang, W. Li, S. Wang, Z. Miao, H. K. Liu and S. Chou, J. Mater. Chem. A, 2018, 6, 6183-6205.

29 N. Yabuuchi, K. Kubota, M. Dahbi and S. Komaba, Chem. Rev., 2014, 114, 11636-11682.

30 H. He, D. Sun, Y. Tang, H. Wang and M. Shao, Energy Storage Mater., 2019, 23, 233-251.

31 T. Chen, Y. Jin, H. Lv, A. Yang, M. Liu, B. Chen, Y. Xie and Q. Chen, Trans. Tianjin Univ., 2020, 26, 208-217.

32 L. Xiao, H. Lu, Y. Fang, M. L. Sushko, Y. Cao, X. Ai, H. Yang and J. Liu, Adv. Energy Mater., 2018, 8, 1703238.

33 X. Yao, Y. Ke, W. Ren, X. Wang, F. Xiong, W. Yang, M. Qin, Q. Li and L. Mai, Adv. Energy Mater., 2019, 9, 1803260.

34 Y. Nishi, Chem. Rec., 2001, 1, 406-413.

35 F. Xie, Z. Xu, Z. Guo and M.-M. Titirici, Prog. Energy, 2020, 2, 042002.

36 D. Saurel, B. Orayech, B. Xiao, D. Carriazo, X. Li and T. Rojo, Adv. Energy Mater., 2018, 8, 1703268.

37 Z. Gao, Y. Zhang, N. Song and X. Li, Mater. Res. Lett., 2017, 5, 69-88.

38 Y. Li, Y. Lu, Q. Meng, A. C. S. Jensen, Q. Zhang, Q. Zhang, Y. Tong, Y. Qi, L. Gu, M. Titirici and Y. Hu, Adv. Energy Mater., 2019, 9, 1902852.

39 M. E. Lee, H. W. Kwak, H. J. Jin and Y. S. Yun, ACS Sustainable Chem. Eng., 2019, 7, 12734-12740.

$40 \mathrm{~J} . \quad$ S. McDonald-Wharry, M. Manley-Harris and K. L. Pickering, Energy Fuels, 2016, 30, 7811-7826.

41 B. Zhang, C. M. Ghimbeu, C. Laberty, C. Vix-Guterl and J.-M. Tarascon, Adv. Energy Mater., 2016, 6, 1501588.

42 D. A. Stevens and J. R. Dahn, J. Electrochem. Soc., 2000, 147, 1271-1273.

43 D. A. Stevens and J. R. Dahn, J. Electrochem. Soc., 2000, 147, 4428-4431.

44 C. Chan, W. Kamitakahara and K. Ho, Synth. Met., 1988, 23, 327-332.

45 C. T. Chan, K. M. Ho and W. A. Kamitakahara, Phys. Rev. B: Condens. Matter Mater. Phys., 1987, 36, 3499-3502.

46 J. S. Weaving, A. Lim, J. Millichamp, T. P. Neville, D. Ledwoch, E. Kendrick, P. F. McMillan, P. R. Shearing, C. A. Howard and D. J. L. Brett, ACS Appl. Energy Mater., 2020, 3, 7474-7484.
47 T. Lyu, X. Lan, L. Liang, X. Lin, C. Hao, Z. Pan, Z. Q. Tian and P. K. Shen, Electrochim. Acta, 2021, 365, 137356.

48 J. Ding, H. Wang, Z. Li, A. Kohandehghan, K. Cui, Z. Xu, B. Zahiri, X. Tan, E. M. Lotfabad, B. C. Olsen and D. Mitlin, ACS Nano, 2013, 7, 11004-11015.

49 Y. Cao, L. Xiao, M. L. Sushko, W. Wang, B. Schwenzer, J. Xiao, Z. Nie, L. V. Saraf, Z. Yang and J. Liu, Nano Lett., 2012, 12, 3783-3787.

50 C. Matei Ghimbeu, J. Górka, V. Simone, L. Simonin, S. Martinet and C. Vix-Guterl, Nano Energy, 2018, 44, 327-335.

51 Y. Li, Y.-S. Hu, M.-M. Titirici, L. Chen and X. Huang, Adv. Energy Mater., 2016, 6, 1600659.

52 P. Bai, Y. He, X. Zou, X. Zhao, P. Xiong and Y. Xu, Adv. Energy Mater., 2018, 8, 1703217.

53 K. Gotoh, T. Ishikawa, S. Shimadzu, N. Yabuuchi, S. Komaba, K. Takeda, A. Goto, K. Deguchi, S. Ohki, K. Hashi, T. Shimizu and H. Ishida, J. Power Sources, 2013, 225, 137-140.

54 Y. Jin, S. Sun, M. Ou, Y. Liu, C. Fan, X. Sun, J. Peng, Y. Li, Y. Qiu, P. Wei, Z. Deng, Y. Xu, J. Han and Y. Huang, ACS Appl. Energy Mater., 2018, 1, 2295-2305.

55 H. Au, H. Alptekin, A. C. S. Jensen, E. Olsson, C. A. O’Keefe, T. Smith, M. Crespo-Ribadeneyra, T. F. Headen, C. P. Grey, Q. Cai, A. J. Drew and M.-M. Titirici, Energy Environ. Sci., 2020, 13, 3469-3479.

56 C. Bommier, T. W. Surta, M. Dolgos and X. Ji, Nano Lett., 2015, 15, 5888-5892.

57 R. Alcántara, P. Lavela, G. F. Ortiz and J. L. Tirado, Electrochem. Solid-State Lett., 2005, 8, 222-225.

58 N. Zhang, Q. Liu, W. Chen, M. Wan, X. Li, L. Wang, L. Xue and W. Zhang, J. Power Sources, 2018, 378, 331-337.

59 X. Dou, I. Hasa, M. Hekmatfar, T. Diemant, R. J. Behm, D. Buchholz and S. Passerini, ChemSusChem, 2017, 10, 2668-2676.

60 J. Ding, H. Wang, Z. Li, K. Cui, D. Karpuzov, X. Tan, A. Kohandehghan and D. Mitlin, Energy Environ. Sci., 2015, 8, 941-955.

61 H. Zhu, F. Shen, W. Luo, S. Zhu, M. Zhao, B. Natarajan, J. Dai, L. Zhou, X. Ji, R. S. Yassar, T. Li and L. Hu, Nano Energy, 2017, 33, 37-44.

62 H. Zhang, W. Zhang, H. Ming, J. Pang, H. Zhang, G. Cao and Y. Yang, Chem. Eng. J., 2018, 341, 280-288.

63 T. Liu and X. Li, Mater. Technol., 2019, 34, 232-245.

64 Z. Schnepp, Angew. Chem., Int. Ed., 2013, 52, 1096-1108.

65 N. Sun, H. Liu and B. Xu, J. Mater. Chem. A, 2015, 3, 20560-20566.

66 J. Górka, C. Vix-Guterl and C. Matei Ghimbeu, C, 2016, $2,24$.

67 J. Zhu, J. Roscow, S. Chandrasekaran, L. Deng, P. Zhang, T. He, K. Wang and L. Huang, ChemSusChem, 2020, 13, 1275-1295.

68 K. Yu, H. Zhao, X. Wang, M. Zhang, R. Dong, Y. Li, Y. Bai, H. Xu and C. Wu, ACS Appl. Mater. Interfaces, 2020, 12, 10544-10553. 
69 H. Liu, X. Liu, H. Wang, Y. Zheng, H. Zhang, J. Shi, W. Liu, M. Huang, J. Kan, X. Zhao and D. Li, ACS Sustainable Chem. Eng., 2019, 7, 12188-12199.

70 X. Ren, S.-D. Xu, S. Liu, L. Chen, D. Zhang and L. Qiu, J. Electroanal. Chem., 2019, 841, 63-72.

71 Y. Li, S. Xu, X. Wu, J. Yu, Y. Wang, Y.-S. Hu, H. Li, L. Chen and X. Huang, J. Mater. Chem. A, 2015, 3, 71-77.

72 Y. Guo, W. Liu, R. Wu, L. Sun, Y. Zhang, Y. Cui, S. Liu, H. Wang and B. Shan, ACS Appl. Mater. Interfaces, 2018, 10, 38376-38386.

73 A. A. Arie, B. Tekin, E. Demir and R. Demir-Cakan, Waste Biomass Valorization, 2020, 11, 3121-3131.

74 R. R. Gaddam, E. Jiang, N. Amiralian, P. K. Annamalai, D. J. Martin, N. A. Kumar and X. S. Zhao, Sustainable Energy Fuels, 2017, 1, 1090-1097.

75 Y. Sun and J. Cheng, Bioresour. Technol., 2002, 83, 1-11.

76 A. Nawirska and M. Kwaśniewska, Food Chem., 2005, 91, 221-225.

77 T. Happi Emaga, C. Robert, S. N. Ronkart, B. Wathelet and M. Paquot, Bioresour. Technol., 2008, 99, 4346-4354.

$78 \mathrm{H}$. Chen, Biotechnology of Lignocellulose, Springer, Netherlands, Dordrecht, 2014, pp. 25-71.

79 Y. Feng, L. Tao, Y. He, Q. Jin, C. Kuai, Y. Zheng, M. Li, Q. Hou, Z. Zheng, F. Lin and H. Huang, J. Mater. Chem. A, 2019, 7, 26954-26965.

80 L. J. Gibson, J. R. Soc., Interface, 2012, 9, 2749-2766.

81 V. Chitra Devi, S. Mothil, R. Sathish Raam and K. Senthilkumar, 2020, pp. 45-63.

82 R. Guo, C. Lv, W. Xu, J. Sun, Y. Zhu, X. Yang, J. Li, J. Sun, L. Zhang and D. Yang, Adv. Energy Mater., 2020, 10, 1903652.

83 Z. Li, C. Bommier, Z. Sen Chong, Z. Jian, T. W. Surta, X. Wang, Z. Xing, J. C. Neuefeind, W. F. Stickle, M. Dolgos, P. A. Greaney and X. Ji, Adv. Energy Mater., 2017, 7, 1602894.

84 K. Kubota, S. Shimadzu, N. Yabuuchi, S. Tominaka, S. Shiraishi, M. Abreu-Sepulveda, A. Manivannan, K. Gotoh, M. Fukunishi, M. Dahbi and S. Komaba, Chem. Mater., 2020, 32, 2961-2977.

85 Y. Queneau, S. Jarosz, B. Lewandowski and J. Fitremann, Adv. Carbohydr. Chem. Biochem., 2007, 217-292.

86 X. Dou, I. Hasa, D. Saurel, C. Vaalma, L. Wu, D. Buchholz, D. Bresser, S. Komaba and S. Passerini, Mater. Today, 2019, 23, 87-104.

87 A. Demirbaş, Energy Explor. Exploit., 2004, 22, 411-419.

88 M.-M. Titirici and M. Antonietti, Chem. Soc. Rev., 2010, 39, 103-116.

89 H. Marsh and F. Rodríguez-Reinoso, Activated Carbon, Elsevier, 2006.

90 D. Saurel, J. Segalini, M. Jauregui, A. Pendashteh, B. Daffos, P. Simon and M. Casas-Cabanas, Energy Storage Mater., 2019, 21, 162-173.

91 P. Ouzilleau, A. E. Gheribi, P. Chartrand, G. Soucy and M. Monthioux, Carbon, 2019, 149, 419-435.

92 B. $\mathrm{Hu}, \mathrm{K}$. Wang, L. Wu, S.-H. Yu, M. Antonietti and M.-M. Titirici, Adv. Mater., 2010, 22, 813-828.
93 X. Liu, C. Yu, H. Hou, Z. Xu, K. Meng, J. Zhu and L. Wang, Environ. Sci. Pollut. Res., 2020, 27, 13467-13476.

94 R. V. P. Antero, A. C. F. Alves, S. B. de Oliveira, S. A. Ojala and S. S. Brum, J. Clean. Prod., 2020, 252, 119899.

95 T. Liu, L. Zhang, B. Cheng and J. Yu, Adv. Energy Mater., 2019, 9, 1803900.

96 X. Sun and Y. Li, Angew. Chem., Int. Ed., 2004, 43, 597-601. 97 X. Cui, M. Antonietti and S.-H. Yu, Small, 2006, 2, 756-759.

98 Y. Mao, H. Duan, B. Xu, L. Zhang, Y. Hu, C. Zhao, Z. Wang, L. Chen and Y. Yang, Energy Environ. Sci., 2012, 5, 7950-7955.

99 W. Chen, M. Wan, Q. Liu, X. Xiong, F. Yu and Y. Huang, Small Methods, 2019, 3, 1800323.

100 Q. Meng, Y. Lu, F. Ding, Q. Zhang, L. Chen and Y.-S. Hu, ACS Energy Lett., 2019, 4, 2608-2612.

101 Y. Mao, H. Duan, B. Xu, L. Zhang, Y. Hu, C. Zhao, Z. Wang, L. Chen and Y. Yang, Energy Environ. Sci., 2012, 5, 7950-7955.

102 Y. Li, M. Chen, B. Liu, Y. Zhang, X. Liang and X. Xia, Adv. Energy Mater., 2020, 10, 2000927.

103 C. Chen, Y. Huang, Y. Zhu, Z. Zhang, Z. Guang, Z. Meng and P. Liu, ACS Sustainable Chem. Eng., 2020, 8, 1497-1506.

104 K. Wang, Y. Xu, Y. Li, V. Dravid, J. Wu and Y. Huang, J. Mater. Chem. A, 2019, 7, 3327-3335.

105 H. Miao, S. Li, Z. Wang, S. Sun, M. Kuang, Z. Liu and J. Yuan, Int. J. Hydrogen Energy, 2017, 42, 28298-28308.

106 A. Gomez-Martin, J. Martinez-Fernandez, M. Ruttert, M. Winter, T. Placke and J. Ramirez-Rico, Chem. Mater., 2019, 31, 7288-7299.

107 N. Sun, Z. Guan, Y. Liu, Y. Cao, Q. Zhu, H. Liu, Z. Wang, P. Zhang and B. Xu, Adv. Energy Mater., 2019, 9, 1901352.

108 E. M. Lotfabad, J. Ding, K. Cui, A. Kohandehghan, W. P. Kalisvaart, M. Hazelton and D. Mitlin, ACS Nano, 2014, 8, 7115-7129.

109 V. Simone, A. Boulineau, A. de Geyer, D. Rouchon, L. Simonin and S. Martinet, J. Energy Chem., 2016, 25, 761-768.

110 D. Sun, B. Luo, H. Wang, Y. Tang, X. Ji and L. Wang, Nano Energy, 2019, 64, 103937.

111 A. Kano, N. Hojo and M. Fujimoto, 228th ECS Meeting, 2014, 1-15.

112 Y. Morikawa, S. Nishimura, R. Hashimoto, M. Ohnuma and A. Yamada, Adv. Energy Mater., 2020, 10, 1903176.

113 X. Zhang, X. Dong, X. Qiu, Y. Cao, C. Wang, Y. Wang and Y. Xia, J. Power Sources, 2020, 476, 228550.

114 S. Alvin, D. Yoon, C. Chandra, H. S. Cahyadi, J.-H. Park, W. Chang, K. Y. Chung and J. Kim, Carbon, 2019, 145, 67-81.

115 R. E. Franklin, Philos. Trans. R. Soc., A, 1951, 209, 196-218.

116 M. Dahbi, M. Kiso, K. Kubota, T. Horiba, T. Chafik, K. Hida, T. Matsuyama and S. Komaba, J. Mater. Chem. A, 2017, 5, 9917-9928.

117 J. Choi, M. E. Lee, S. Lee, H.-J. Jin and Y. S. Yun, ACS Appl. Energy Mater., 2019, 2, 1185-1191.

118 A. Sadezky, H. Muckenhuber, H. Grothe, R. Niessner and U. Pöschl, Carbon, 2005, 43, 1731-1742. 
119 A. C. Ferrari and J. Robertson, Phys. Rev. B: Condens. Matter Mater. Phys., 2000, 61, 14095-14107.

120 L. Niu, Z. Li, W. Hong, J. Sun, Z. Wang, L. Ma, J. Wang and S. Yang, Electrochim. Acta, 2013, 108, 666-673.

121 H. Xie, Z. Wu, Z. Wang, N. Qin, Y. Li, Y. Cao and Z. Lu, J. Mater. Chem. A, 2020, 8, 3606-3612.

122 P. Ehrburger, N. Pusset and P. Dziedzinl, Carbon, 1992, 30, 1105-1109.

123 Z. Li, H. Peng, R. Liu, Y. Mo, B. Cao, W. Lai, X. Li, L. Pan and Y. Chen, J. Power Sources, 2020, 457, 228022.

124 M. Velický, P. S. Toth, C. R. Woods, K. S. Novoselov and R. A. W. Dryfe, J. Phys. Chem. C, 2019, 123, 11677-11685.

125 Q. Lin, J. Zhang, W. Lv, J. Ma, Y. He, F. Kang and Q. Yang, Small, 2020, 16, 1902603.

126 E. Olsson, G. Chai, M. Dove and Q. Cai, Nanoscale, 2019, 11, 5274-5284.

127 Z. Liang, X. Fan, W. Zheng and D. J. Singh, ACS Appl. Mater. Interfaces, 2017, 9, 17076-17084.

128 Y. Zhang, N. Zhang, W. Chen, Z. Rao, J. Wu, L. Xue and W. Zhang, Energy Technol., 2019, 7, 1900779.

129 W. Luo, C. Bommier, Z. Jian, X. Li, R. Carter, S. Vail, Y. Lu, J.-J. Lee and X. Ji, ACS Appl. Mater. Interfaces, 2015, 7, 2626-2631.

130 M. Duan, F. Zhu, G. Zhao, J. Hu, H. Zhang, G. Ren, Y. Meng and Z. Fan, Microporous Mesoporous Mater., 2020, 306, 110433.

131 Y. Wang, Y. Li, S. S. Mao, D. Ye, W. Liu, R. Guo, Z. Feng, J. Kong and J. Xie, Sustainable Energy Fuels, 2019, 3, 717-722.

132 K. Xu, G. Du, T. Zhong, D. Chen, X. Lin, Z. Zheng and S. Wang, J. Taiwan Inst. Chem. Eng., 2020, 109, 79-89.

$133 \mathrm{Y} . \mathrm{Hu}, \mathrm{L}$. Shen, X. Wei, Z. Long, X. Guo and X. Qiu, ChemistrySelect, 2019, 4, 6445-6450.

134 L. Qie, W. Chen, X. Xiong, C. Hu, F. Zou, P. Hu and Y. Huang, Adv. Sci., 2015, 2, 1500195.

135 H. Wan, X. Ju, T. He, T. Chen, Y. Zhou, C. Zhang, J. Wang, Y. Xu, B. Yao, W. Zhuang and X. Du, J. Alloys Compd., 2021, 863, 158078.

136 P. Wang, B. Qiao, Y. Du, Y. Li, X. Zhou, Z. Dai and J. Bao, J. Phys. Chem. C, 2015, 119, 21336-21344.

137 Z. Li, C. Bommier, Z. Sen Chong, Z. Jian, T. W. Surta, X. Wang, Z. Xing, J. C. Neuefeind, W. F. Stickle, M. Dolgos, P. A. Greaney and X. Ji, Adv. Energy Mater., 2017, 7, 1602894.

138 K. C. Wasalathilake, G. A. Ayoko and C. Yan, Carbon, 2018, 140, 276-285.

139 M. Inagaki, M. Toyoda, Y. Soneda and T. Morishita, Carbon, 2018, 132, 104-140.
140 Y. Li, M. Chen, B. Liu, Y. Zhang, X. Liang and X. Xia, Adv. Energy Mater., 2020, 10, 2000927.

141 H. He, D. Huang, Y. Tang, Q. Wang, X. Ji, H. Wang and Z. Guo, Nano Energy, 2019, 57, 728-736.

142 D. Luo, P. Han, L. Shi, J. Huang, J. Yu, Y. Lin, J. Du, B. Yang, C. Li, C. Zhu and J. Xu, Appl. Surf. Sci., 2018, 462, 713-719.

143 Y. Qiao, R. Han, Y. Pang, Z. Lu, J. Zhao, X. Cheng, H. Zhang, Z. Yang, S. Yang and Y. Liu, J. Mater. Chem. A, 2019, 7, 11400-11407.

144 Z. Li, L. Ma, T. W. Surta, C. Bommier, Z. Jian, Z. Xing, W. F. Stickle, M. Dolgos, K. Amine, J. Lu, T. Wu and X. Ji, ACS Energy Lett., 2016, 1, 395-401.

145 L. Yang, M. Hu, H. Zhang, W. Yang and R. Lv, J. Colloid Interface Sci., 2020, 566, 257-264.

146 E. Redondo, J. Carretero-González, E. Goikolea, J. Ségalini and R. Mysyk, Electrochim. Acta, 2015, 160, 178-184.

147 J. Mao, T. Zhou, Y. Zheng, H. Gao, H. K. Liu and Z. Guo, J. Mater. Chem. A, 2018, 6, 3284-3303.

148 L. Li, Y. Zheng, S. Zhang, J. Yang, Z. Shao and Z. Guo, Energy Environ. Sci., 2018, 11, 2310-2340.

149 M. Carboni, J. Manzi, A. R. Armstrong, J. Billaud, S. Brutti and R. Younesi, ChemElectroChem, 2019, 6, 1745-1753.

150 S. Komaba, W. Murata, T. Ishikawa, N. Yabuuchi, T. Ozeki, T. Nakayama, A. Ogata, K. Gotoh and K. Fujiwara, Adv. Funct. Mater., 2011, 21, 3859-3867.

151 J. Fondard, E. Irisarri, C. Courrèges, M. R. Palacin, A. Ponrouch and R. Dedryvère, J. Electrochem. Soc., 2020, 167, 070526.

152 W. Luo, C. Bommier, Z. Jian, X. Li, R. Carter, S. Vail, Y. Lu, J.-J. Lee and X. Ji, ACS Appl. Mater. Interfaces, 2015, 7, 2626-2631.

153 C. Wang, J. Huang, J. Li, L. Cao, Q. Chen, C. Qian and S. Chen, ChemElectroChem, 2020, 7, 201-211.

154 E. Olsson, J. Cottom, H. Au, M.-M. Titirici and Q. Cai, Carbon, 2021, 177, 226-243.

155 M. Inagaki, Carbon, 2012, 50, 3247-3266.

156 M. M. Titirici, H. Alptekin, H. Au, A. C. Jensen, E. Olsson, M. Goktas, T. F. Headen, P. Adelhelm, Q. Cai and A. J. Drew, ACS Appl. Energy Mater., 2020, 3, 9918-9927.

157 A. Kano, N. Hojo, S. Ito, M. Fujimoto and K. Nakura, Meet. Abstr., 2015, MA2015-02, 221.

158 E. Olsson, J. Cottom, H. Au, Z. Guo, A. C. S. Jensen, H. Alptekin, A. J. Drew, M. Titirici and Q. Cai, Adv. Funct. Mater., 2020, 30, 1908209.

159 Y. Cao, L. Xiao, M. L. Sushko, W. Wang, B. Schwenzer, J. Xiao, Z. Nie, L. V. Saraf, Z. Yang and J. Liu, Nano Lett., 2012, 12, 3783-3787. 